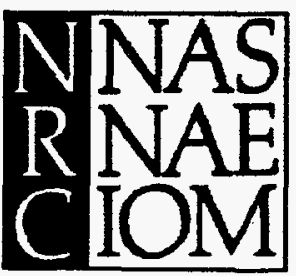

\title{
Assessment of the Current Status of Basic Nuclear Data Compilations
}

\author{
Report of a Meeting on October 3 and 4, 1991 \\ Oak Ridge National Laboratory
}

\section{Panel on Basic Nuclear Data Compilations}

\author{
DISCLAIMER
}

This report was prepared as an account of work sponsored by an agency of the United States Government. Neither the United States Government nor any agency thereof, nor any of their employees, makes any warranty, express or implied, or assumes any legal liability or responsibility for the accuracy, completeness, or usefulness of any information, apparatus, product, or process disclosed, or represents that its use would not infringe privately owned rights. Reference herein to any specific commercial product, process, or service by trade name, trademark, manufacturer, or otherwise does not necessarily constitute or imply its endorsement, recommendation, or favoring by the United States Government or any agency thereof. The views and opinions of authors expressed herein do not necessarily state or reflect those of the United States Government or any agency thereof. 


\section{DISCLAIMER}

Portions of this document may be illegible in electronic image products. Images are produced from the best available original document. 


\title{
Assessment of the Current Status of Basic Nuclear Data Compilations
}

\author{
Report of a Meeting on October 3 and 4, 1991 \\ Oak Ridge National Laboratory
}

Panel on Basic Nuclear Data Compilations

Board on Physics and Astronomy

Commission on Physical Sciences, Mathematics, and Applications

National Research Council

National Academy Press

Washington, D.C. 1992 
NOTICE: The project that is the subject of this report was approved by the Governing Board of the National Research Council, whose members are drawn from the councils of the National Academy of Sciences, the National Academy of Engineering, and the Institute of Medicine. The members of the panel responsible for the report were chosen for their special competences and with regard for appropriate balance.

This report has been reviewed by a group other than the authors according to procedures approved by a Report Review Committee consisting of members of the National Academy of Sciences, the National Academy of Engineering, and the Institute of Medicine.

The National Academy of Sciences is a private, nonprofit, self-perpetuating society of distinguished scholars engaged in scientific and engineering research, dedicated to the furtherance of science and technology and to their use for the general welfare. Upon the authority of the charter granted to it by the Congress in 1863, the Academy has a mandate that requires it to advise the federal government on scientiflc and technical matters. Dr. Frank Press is president of the National Academy of Sciences.

The National Academy of Engineering was established in 1964, under the charter of the National Academy of Sciences, as a parallel organization of outstanding engineers. It is autonomous in its administration and in the selection of its members, sharing with the National Academy of Sciences the responsibility for advising the federal government. The National Academy of Engineering also sponsors engineering programs aimed at meeting national needs, encourages education and research, and recognizes the superior achievements of engineers. Dr. Robert $M$. White is president of the National Academy of Engineering.

The Institute of Medicine was established in 1970 by the National Academy of Sciences to secure the services of eminent members of appropriate professions in the examination of policy matters pertaining to the health of the public. The Institute acts under the responsibility given to the National Academy of Sciences by its congressional charter to be an adviser to the federal government and, upon its own initiative, to identify issues of medical care, research, and education. Dr. Kenneth $\mathbf{I}$. Shine is president of the Institute of Medicine.

The National Research Council was established by the National Academy of Sciences in 1916 to associate the broad community of science and technology with the Academy's purposes of furthering knowledge and of advising the federal government. Functioning in accordance with general policies determined by the Academy, the Council has become the principal operating agency of both the National Academy of Sciences and the National Academy of Engineering in providing services to the govemment, the public, and the scientific and engineering communities. The Council is administered jointly by both Academies and the Institute of Medicine. Dr. Frank Press and Dr. Robert M. White are chairman and vice chairman, respectively, of the National Research Council.

This project was supported by the Department of Energy under Contract No. DE-FG05-89ER40505.

Additional copies of this report are available from the

Board on Physics and Astronomy

National Research Council

2101 Constitution Avenue, NW

Washington, DC 20418

Printed in the United States of America 
JOLIE A. CIZEWSKI, Rutgers University, Chair RICHARD F. CASTEN, Brookhaven National Laboratory JOANNA FOWLER, Brookhaven National Laboratory JERRY GARRETT, Oak Ridge National Laboratory ROBERT C. HAIGHT, Los Alamos National Laboratory KIRBY W. KEMPER, Florida State University

JAMES P. VARY, Iowa State University

Government Liaison Representatives

RICHARD MEYER, Department of Energy

STANLEY WHETSTONE, Department of Energy

ROBERT L. RIEMER, Senior Program Officer 
BOARD ON PHYSICS AND ASTRONOMY

FRANK D. DRAKE, University of California, Santa Cruz, Chair LLOYD ARMSTRONG, Johns Hopkins University HOWARD C. BERG, Harvard University WILLIAM F. BRINKMAN, AT\&T Bell Laboratories PRAVEEN CHAUDHARI, IBM T.J. Watson Research Center GEORGE W. CLARK, Massachusetts Institute of Technology JEROME I. FRIEDMAN, Massachusetts Institute of Technology HAROLD P. FURTH, Princeton University MARTHA P. HAYNES, Cornell University CHARLES F. KENNEL, University of California, Los Angeles GILLIAN KNAPP, Princeton University STEVEN E. KOONIN, California Institute of Technology ALBERT NARATH, Sandia National Laboratories GEORGE W. PARSHALL, E.I. du Pont de Nemours \& Company, Inc. JOSEPH M. PROUD, GTE Laboratories Incorporated VERA RUBIN, Carnegie Institution of Washington DAVID N. SCHRAMM, University of Chicago DANIEL TSUI, Princeton University

DONALD C. SHAPERO, Director ROBERT L. RIEMER, Associate Director RONALD D. TAYLOR, Senior Program Officer LAWRENCE D. PICHA, Staff Associate MARY RIENDEAU, Administrative Secretary ANNE K. SIMMONS, Senior Secretary 
NORMAN HACKERMAN, Robert A. Welch Foundation, Chair PETER J. BICKEL, University of California, Berkeley GEORGE F. CARRIER, Harvard University GEORGE W. CLARK, Massachusetts Institute of Technology DEAN E. EASTMAN, IBM T.J. Watson Research Center MARYE ANNE FOX, University of Texas PHILLIP A. GRIFFITHS, Institute for Advanced Study NEAL F. LANE, Rice University ROBERT W. LUCKY, AT\&T Bell Laboratories CLAIRE E. MAX, Lawrence Livermore National Laboratory CHRISTOPHER F. McKEE, University of California, Berkeley JAMES W. MITCHELL, AT\&T Bell Laboratories RICHARD S. NICHOLSON, American Association for the Advancement of Science ALAN SCHRIESHEIM, Argonne National Laboratory KENNETH G. WILSON, Ohio State University

NORMAN METZGER, Executive Director 


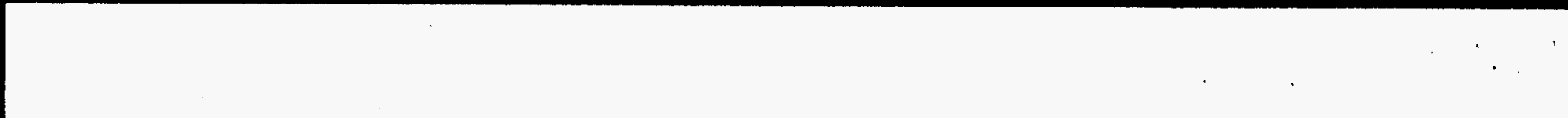




\section{Contents}

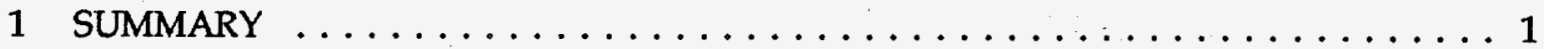

2 INTRODUCTION $\ldots \ldots \ldots \ldots \ldots \ldots \ldots \ldots \ldots \ldots \ldots \ldots \ldots \ldots$

3 CURRENT STATUS $\ldots \ldots \ldots \ldots \ldots \ldots \ldots \ldots \ldots \ldots \ldots \ldots \ldots \ldots \ldots \ldots \ldots \ldots$

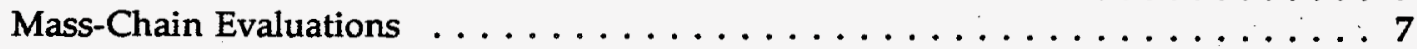

U.S. Data Centers . . . . . . . . . . . . . . . . . 15

Foreign Data Centers . . . . . . . . . . . . . . . . . 16

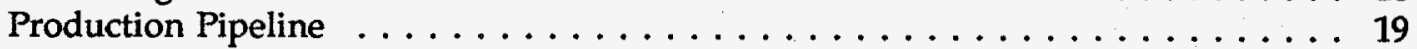

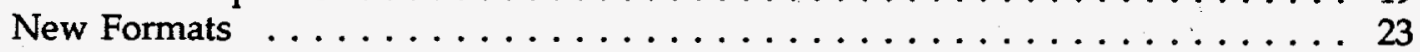

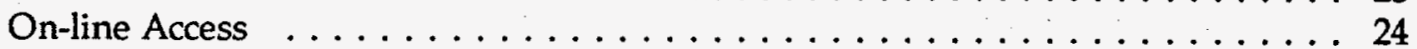

Table of Isotopes . . . . . . . . . . . . . . . . . . 26

Support for Basic Nuclear Data Evaluation Activities . . . . . . . . . 27

4 FUTURE DIRECTIONS IN NUCLEAR DATA EVALUATIONS . . . . . . . . . 29

Electronic Publication and Dissemination . . . . . . . . . . . . . . . 29

Proposals from BNL and LBL $\ldots \ldots \ldots \ldots \ldots \ldots \ldots \ldots \ldots \ldots, \ldots \ldots$

MacNuclide ........................... 34

The User's Needs $\ldots \ldots \ldots \ldots \ldots \ldots \ldots \ldots \ldots \ldots \ldots \ldots \ldots . \ldots \ldots$

Applications to Applied Fields $\ldots \ldots \ldots \ldots \ldots \ldots \ldots \ldots \ldots \ldots \ldots \ldots \ldots, 34$

New Nuclear Data Initiatives in Nuclear Science $\ldots \ldots \ldots \ldots \ldots \ldots .35$

5 THE FUTURE OF THE PANEL $\ldots \ldots \ldots \ldots \ldots \ldots \ldots \ldots \ldots \ldots \ldots$

APPENDIX: AGENDA AND ATTENDEES $\ldots \ldots \ldots \ldots \ldots \ldots \ldots \ldots \ldots$ 


\section{1 Summary}

The Panel on Basic Nuclear Data Compilations believes that it is important to provide the user with an evaluated nuclear database of the highest quality, dependability, and currency. It is also important that the evaluated nuclear data are easily accessible to the user. In the past the panel concentrated its concern on the cycle time for the publication of A-chain evaluations. However, the panel now recognizes that publication cycle time is no longer the appropriate goal. Sometime in the future, publication of the evaluated A-chains will evolve from the present hard-copy Nuclear Data Sheets on library shelves to purely electronic publication, with the advent of universal access to terminals and the nuclear databases. Therefore, the literature cut-off date in the Evaluated Nuclear Structure Data File (ENSDF) is rapidly becoming the only important measure of the currency of an evaluated A-chain. Also, it has become exceedingly important to ensure that access to the databases is as user-friendly as possible and to enable electronic publication of the evaluated data files. Considerable progress has been made in these areas: use of the on-line systems has almost doubled in the past year, and there has been initial development of tools for electronic evaluation, publication, and dissemination.

Currently, the nuclear data effort is in transition between the traditional and future methods of dissemination of the evaluated data. Also, many of the factors that adversely affect the publication cycle time simultaneously affect the currency of the evaluated nuclear database. Therefore, the panel continues to examine factors that can influence cycle time: the number of evaluators, the frequency with which an evaluation can be updated, the review of the evaluation, and the production of the evaluation, which currently exists as a hard-copy issue of Nuclear Data Sheets.

The panel heard reports from the individual U.S. data centers. While many of the individual evaluators in the U.S. Network have attained the expected productivity of $2.5 \mathrm{~A}$-chains per full-time-equivalent (FTE) evaluator per year, this level is still not achieved by every U.S. evaluator. The panel was pleased to learn that some A-chains were submitted as continuous evaluations, which represent an efficient mechanism to achieve a highly current evaluated nuclear database. The panel hopes that this procedure will soon be adopted for all A-chains evaluated after 1989. The panel anticipates that the measure of productivity will evolve as evaluators complete more continuous evaluations. For example, each center could strive to minimize the number of A-chains whose literature cut-off date is more than 5 years old, normalized to the total responsibility of that center and the number of FTE evaluators. The measure of productivity would then be how few evaluations are outdated, rather than only how many have been completed. While the measure of productivity will evolve, at least for the near future, the number of FTE evaluators cannot decrease. To shorten the cycle time for A-chains toward the 5-year target, even greater productivity will be required from each evaluator. However, at least for the short term, the panel strongly recommends that the number of FTE evaluators in the United States not decrease. However, the panel recommends that the productivity of individual evaluators, individual centers, and the U.S. Network as a whole be re-examined so that as many evaluations as possible can be submitted each year, either as complete evaluations, or in update or continuous formats.

The assignment of A-chains to centers has been historic. Redistribution of resources between the U.S. centers has occurred over the past years, and this has also affected the number of FTE evaluators associated with each center. The panel recommends that the U.S. Network be flexible 
in the assignment of A-chains to individual centers (and evaluators) and as a group concentrate on evaluating those A-chains that are the most outdated, irrespective of which center has traditionally had that responsibility.

The panel is satisfied with the current status of the newly transferred responsibility for $A=5-20$, and was pleased to learn that a new evaluation of $A=21-44$ was published in early 1991 . The panel encourages the International Network to help coordinate the future efforts in the $A=21-44$ region.

The appropriate level of productivity of the foreign centers is difficult to assess. The withdrawal of the German effort persists. The Japanese and Swedish efforts each produced one evaluation but still are far from achieving even their own expressed expectations. On the positive side, the Kuwaiti center is being rebuilt and should be operating again in about 2 years. Also, the French center exceeded the productivity of any U.S. center, submitting two evaluations and one continuous evaluation for its 0.5 FTE evaluator. This indicates that a high level of productivity can be attained. The panel was also encouraged by the interest of Eastern European countries in joining the International Network and supports any efforts that can expand the resources available for data evaluation. ENSDF is a resource for all highly developed nations. The panel recommends that new initiatives be taken to increase effective foreign involvement in the evaluation process, which is the basis for this database.

The production pipeline remains a major problem in attaining the most current evaluated nuclear database, and the review process remains the major source of this problem. The first attempt to alleviate the bottleneck in the review process was to distribute the responsibility to essentially all of the evaluators in the International Network. Every full-time evaluator is now expected to do two reviews of evaluated A-chains each year. This does not appear to have solved the problem, since the average time spent in review increased in 1991 to 5.3 months. Apparently, much of this delay, and the delay in most steps of the pipeline, arises from "downtime" when no action is taken on the work for significant periods of time. The panel recommends that the Network immediately adopt an algorithm that will minimize this downtime and that the NNDC and/or the Department of Energy's nuclear physics program manager enforce its implementation. However, this solves only one problem with the review bottleneck.

The panel was disappointed by the sources and types of errors in the evaluations presented for review for 1991. To eliminate the necessity of a second evaluation by a reviewer, the panel makes three recommendations, two repeated directly from the 1990 report: (1) Evaluators should strive for the highest accuracy in the initial drafts, (2) computer checking codes should be exploited as much as possible, and (3) the possible implementation of internal review, in which an evaluation is reviewed by an evaluator at the same data center, should be tried and evaluated.

The panel is pleased with the status of the production of the 8th edition of the Table of Isotopes by the Isotopes Project at the Lawrence Berkeley Laboratory (LBL). The progress of this effort should be monitored semiannually. The LBL group anticipates a camera-ready book in early 1993. Since the new Table will use data from ENSDF, it is especially important that severely out-of-date evaluations be made current. The panel recommends that the U.S. Network assume whatever responsibility is necessary to ensure that the nuclear structure database is as current as possible when the production of the Table begins. In particular, the panel recommends that the U.S. Network not only make sure that all A-chains that are the responsibility of U.S. centers are as current as possible, but also that the U.S. Network work with the foreign centers to assist them with whatever means are necessary to bring the foreign responsibilities up to date.

The panel continues to examine the future needs of users of evaluated nuclear structure data and how these data can be best disseminated. The panel is convinced that it cannot overemphasize the need for electronic publication and dissemination of evaluated nuclear data, as well as electronic access to published, and even "about to be published," nuclear data prior to full evaluation. The overall goal of the electronic publication and dissemination efforts should be to reduce the interval between completion of data analysis by researchers and the time those same data are evaluated and made available to other researchers in a convenient medium. 
Increasingly, the preferred medium is electronic. It is also important that software be developed so that the user can easily transfer information in ENSDF for manipulation and analysis on other computer systems. The panel recommends that the U.S. Network work as a group to develop a cohesive, detailed proposal for future electronic publication and dissemination of the evaluated nuclear structure data.

Easily accessible, accurate, current nuclear data are becoming increasingly important in today's highly technical, multidisciplinary world, with uses in basic and applied research and development. The present report specifically addresses the needs in two areas of basic nuclear science research, high-spin gamma-ray spectroscopy and the structure of nuclei far from the valley of stability. The panel recommends that the Nuclear Data Network work with the high-spin nuclear structure community to develop a database that meets the needs of the producers, the users, and the eventual evaluators of these data. It is important that the needs of users in other areas of basic and applied research and development be assessed, and that the Nuclear Data Network be attuned to those needs and develop the tools that best address those needs.

The panel recommends that the Nuclear Data Network investigate the following with the high-spin nuclear structure community:

1. The possibility of providing the current data of the various high-spin databases to the nuclear science community through the Nuclear Data Network;

2. A method of maintaining an up-to-date high-spin database; and

3. A technique for providing such data to interested users in a tabular format that can be used directly for computing secondary quantities of scientific interest.

The panel also recommends that the Nuclear Data Network examine how it incorporates results of nuclei far from stability and that it determine whether current methods will be adequate with the advent of major new facilities with radioactive beams.

While much of this report details the work of individual U.S. data centers, it is also appropriate to focus on the efforts and productivity of the entire U.S. Network. This is especially true now, given the limitations on the resources that are available for this effort. The panel recommends that all members of the U.S. Network work together to enhance their collective productivity and accuracy, to develop new methods to disseminate the evaluated data, and to continue to examine how their efforts can be focused to meet the needs of their users. The panel encourages the DOE nuclear physics program manager to help coordinate these efforts.

The panel looks forward to a decrease in the time spent in the production pipeline, an ENSDF file in which no A-chain evaluation is more than 5 years old, a new edition of the Table of Isotopes, and the advent of electronic publication of the evaluated A-chains. While more work needs to be done, these goals seem attainable in the near future. 



\section{2 \\ Introduction}

The Panel on Basic Nuclear Data Compilations met at Oak Ridge National Laboratory (ORNL) on October 3 and 4, 1991. Five panel members, as well as Drs. Jerry Garrett and Robert L. Riemer, were present, together with several other individuals with various responsibilities and interests in the U.S. Nuclear Data Network (USNDN). Dr. Garrett attended the October meeting as a guest of the panel and became a member of the panel late in 1991. The USNDN and the USNDN Subcommittee on Evaluated Nuclear Structure Data File (ENSDF) Formats and Procedures held meetings at ORNL on October 1 and 2, and also met jointly with the panel on October 3. Status reports were presented to the panel on the five U.S. evaluation centers, located at Brookhaven National Laboratory (BNL), Idaho National Engineering Laboratory (INEL), Lawrence Berkeley Laboratory (LBL), Oak Ridge National Laboratory (ORNL), and Triangle Universities Nuclear Laboratory (TUNL). The reports from the centers outlined the status of their mass-chain evaluations and of a number of other projects related to this work; these are discussed in more detail in the section "U.S. Data Centers" in Chapter 3. Written summaries of these status reports were mailed to the panel members one week prior to the meeting. This practice was found to be very useful.

The panel continues to be impressed with the integrity, dedication, and enthusiasm of each of these groups, and the panel is grateful to each of the individuals involved in the U.S. Network. In the 1990 report the panel noted the coordination of the Network in taking major steps to attain an up-to-date ENSDF file and to make the review process in the pipeline more efficient. The panel believed that the USNDN had responded in an innovative manner to the suggestions of the panel. Unfortunately, there continues to be competition, rather than cooperation, between the centers, and this competition is not always constructive. This is a critical time in which the needs for evaluated nuclear structure data, as well as the process by which this evaluation occurs, are being reexamined. Significant progress needs to be made toward eliminating severely out-of-date evaluations, increasing the efficiency of the evaluation process, making the production pipeline more efficient, working toward fully electronic production and dissemination of the evaluated data, and accomplishing these goals with finite resources. The panel hopes that everyone involved with the production, evaluation, and dissemination of nuclear structure data can work together to attain this progress.

The panel expresses its special thanks to members of the ORNL Nuclear Data Project (NDP) for their warm and thoughtful hospitality and for the organization involved in hosting this meeting. The panel would also like to thank the representatives of the U.S. data centers, as well as Prof. Craig Stone and Dr. C. Michael Lederer, for their written reports and presentations during the meeting. The panel is grateful to Dr. Mulki Bhat of BNL for providing the final 1991 statistics needed for this report. 


\section{3 \\ Current Status}

\section{MASS-CHAIN EVALUATIONS}

Mass-chain evaluations are compiled by international cooperation through the Nuclear Structure and Decay Data (NSDD) Network. Table 1 lists the assignments and locations of the U.S. and foreign centers. In the past 2 years considerable redistribution of A-chain assignments has occurred, including the 20 A-chains that had been assigned to German evaluators. The result is that 167 A-chains are assigned to U.S. evaluators and 99 to foreign evaluators. These numbers reflect the current status of temporary assignments.

Compilations for $A<45$ are published in Nuclear Physics $A$. The transfer of $A=5-20$ from Prof. Ajzenberg-Selove at the University of Pennsylvania to Profs. H.R. Weller and D.R. Tilley at Triangle Universities Nuclear Laboratory has been completed. Professors Weller and Tilley have assumed responsibility for the $A=3-20$ compilations and anticipate producing a draft of $A=16$ in early 1992. The $A=21-44$ compilation prepared by Profs. $P$. Endt and $C$. van der Leun was published in 1991.

The mass chains $A>44$ are distributed throughout the rest of the Nuclear Structure and Decay Data Network. There were 16 worldwide full-time-equivalent (FTE) evaluators in 1991, with the United States contributing 7.5 to the international effort. Although the Kuwaiti center was destroyed, it is being rebuilt and could be operational within the next 2 years. There has also been some interest from Eastern European countries in joining the International Network.

Evaluations for $A>44$ are published in Nuclear Data Sheets, which is produced by the National Nuclear Data Center (NNDC) at Brookhaven National Laboratory (BNL) and published by Academic Press. The NNDC also maintains the databases and the on-line access to these, which is available through a variety of computer networks. Twenty-nine A-chains appeared in Nuclear Data Sheets in 1991, including 17 published in update format. This year the number of published pages of A-chains has again come close to the number of pages made available by the publishers. In addition to the publication of the evaluations in hard copy, a major form of dissemination is now via computer network access to the databases. When an evaluation is sent to the publisher, the final version is added to the on-line database. In addition, the user can access a complete evaluation before it has been reviewed, and be aware that this is the case. Although traditionally a mass chain was evaluated only on a regular, typically 5-year, cycle time, the continuous evaluation mode was recently adopted by the Nuclear Data Network, and this year the initial products became available. While continuous evaluations will not be published in hard copy, they will be available via on-line access, and the availability is indicated in the Cumulated Index to A-chains in each issue of the Nuclear Data Sheets.

Table 2 lists the A-chains that have been published as of 1991 and those that are currently in the pipeline. Table 3 summarizes the status of A-chains that are not presented in Table 2. Table 4 lists the A-chains for which a continuous evaluation was completed in 1991. Figure 1 shows the status of all A-chains plotted against literature cut-off dates; essentially the same information is displayed in Figure 2, but in the form of a Chart of the Nuclides. 
TABLE 1 MASS-CHAIN EVALUATION ASSIGNMENTS 1991 ${ }^{\dagger}$

\begin{tabular}{|c|c|c|}
\hline Center & $\begin{array}{l}\text { Assignment } \\
\text { Perm/Temp }\end{array}$ & Number \\
\hline BNL & $\begin{array}{l}45-50,57,58,65-73,94-97,99,136-148,150,152,165,199, \\
211^{*}, 212^{*}\end{array}$ & $39 / 2$ \\
\hline INEL & $87,153-163$ & 12 \\
\hline LBL & $\begin{array}{l}59^{*}, 76^{*}, 79^{*}, 80^{*}, 81^{*}, 83^{*}, 89-93,167-194,206,210-212,215 \\
219,223,227\end{array}$ & $41 / 6$ \\
\hline ORNL & $\begin{array}{l}81-85,200-205,207-209,213,214,216-218,220-222,224-226 \\
228-237,239,241,243,245-266\end{array}$ & 60 \\
\hline TUNL & $3-20$ & 18 \\
\hline Kuwait & 74-80 & 7 \\
\hline France & $101-110$ & 10 \\
\hline Belgium & $111-117$ & 7 \\
\hline Japan & $118-129,177^{*}$ & $12 / 1$ \\
\hline USSR & $1-2,82^{\star}, 86,88,130-135,164,166,238,240,242,244$ & $16 / 1$ \\
\hline Sweden & $59-63,90^{*}$ & $5 / 1$ \\
\hline Canada & $64,98,100,149,151$ & 5 \\
\hline Netherlands & $21-44$ & 24 \\
\hline China & $51-56,61^{*}, 170^{\star}, 172^{*}, 195-198$ & $10 / 3$ \\
\hline Taiwan & $60^{*}, 62^{*}, 63^{*}, 72^{*}, 73^{*}$ & $0 / 5$ \\
\hline
\end{tabular}

$\dagger$ Assignments as of December 31, 1991.

* Temporary assignment. 
TABLE 2 NUCLEAR DATA SHEETS PUBLICATION STATUS 1985-1991

\begin{tabular}{|c|c|c|c|c|}
\hline $\begin{array}{l}\text { A-Chain } \\
\text { Number }\end{array}$ & $\begin{array}{l}\text { Submitted } \\
\text { to NNDC }\end{array}$ & Months in Pipeline* & Issue & Publication Date \\
\hline 161 & $11 / 83$ & 14 & $43-1$ & $1 / 85$ \\
\hline 171 & $2 / 84$ & 11 & $43-2$ & $2 / 85$ \\
\hline 240 & $3 / 83$ & 23 & $43-2$ & $2 / 85$ \\
\hline 181 & $9 / 83$ & 18 & $43-3$ & $3 / 85$ \\
\hline 207 & $3 / 84$ & 12 & $43-3$ & $3 / 85$ \\
\hline 53 & $3 / 84$ & 13 & $43-4$ & $4 / 85$ \\
\hline 142 & $5 / 84$ & 11 & $43-4$ & $4 / 85$ \\
\hline 94 & $9 / 84$ & 9 & $44-2$ & $5 / 85$ \\
\hline 241 & $9 / 84$ & 8 & $44-2$ & $5 / 85$ \\
\hline 55 & $3 / 84$ & 15 & $44-3$ & $5 / 85$ \\
\hline 162 & $9 / 84$ & 10 & $44-4$ & $7 / 85$ \\
\hline 141 & $8 / 84$ & 11 & $45-1$ & $7 / 85$ \\
\hline 205 & $11 / 84$ & 9 & $45-1$ & $7 / 85$ \\
\hline 103 & $9 / 84$ & 11 & $45-3$ & $8 / 85$ \\
\hline 242 & $10 / 84$ & 10 & $45-3$ & $8 / 85$ \\
\hline 48 & $11 / 84$ & 9 & $45-4$ & $9 / 85$ \\
\hline 101 & $9 / 84$ & 12 & $45-4$ & $9 / 85$ \\
\hline 149 & $12 / 84$ & 10 & $46-1$ & $10 / 85$ \\
\hline 160 & $9 / 84$ & 13 & $46-2$ & $10 / 85$ \\
\hline 203 & $5 / 85$ & 5 & $46-2$ & $10 / 85$ \\
\hline 81 & $2 / 85$ & 10 & $46-4$ & $12 / 85$ \\
\hline 97 & $9 / 84$ & 16 & $46-4$ & $12 / 85$ \\
\hline 57 & $12 / 84$ & 13 & $47-1$ & $1 / 86$ \\
\hline 65 & $3 / 85$ & 11 & $47-1$ & $1 / 86$ \\
\hline 105 & $4 / 85$ & 11 & $47-2$ & $2 / 86$ \\
\hline 164 & $7 / 84$ & 19 & $47-2$ & $2 / 86$ \\
\hline 208 & $11 / 84$ & 18 & $47-4$ & $4 / 86$ \\
\hline 47 & $11 / 84$ & 18 & $48-1$ & $5 / 86$ \\
\hline 51 & $6 / 85$ & 11 & $48-1$ & $5 / 86$ \\
\hline 150 & $6 / 84$ & 25 & $48-2$ & $7 / 86$ \\
\hline 60 & $8 / 85$ & 11 & $48-2$ & $7 / 86$ \\
\hline 49 & $5 / 85$ & 16 & $48-4$ & $9 / 86$ \\
\hline 143 & $3 / 85$ & 18 & $48-4$ & $9 / 86$ \\
\hline 99 & $9 / 85$ & 11 & $48-4$ & $9 / 86$ \\
\hline 237 & $6 / 85$ & 15 & $49-1$ & $9 / 86$ \\
\hline $\begin{array}{l}216,220 \\
224,228\end{array}$ & $9 / 85$ & 13 & $49-1$ & $9 / 86$ \\
\hline 145 & $7 / 85$ & 15 & $49-1$ & $9 / 86$ \\
\hline 122 & $8 / 85$ & 14 & $49-2$ & $11 / 86$ \\
\hline 46 & $10 / 85$ & 13 & $49-2$ & $11 / 86$ \\
\hline 156 & $10 / 85$ & 13 & $49-2$ & $11 / 86$ \\
\hline 83 & $12 / 85$ & 12 & $49-4$ & $12 / 86$ \\
\hline
\end{tabular}




\begin{tabular}{|c|c|c|c|c|}
\hline $\begin{array}{l}\text { A-Chain } \\
\text { Number }\end{array}$ & $\begin{array}{r}\text { Submitted } \\
\text { to NNDC }\end{array}$ & Months in Pipeline* & Issue & Publication Date \\
\hline 133 & $2 / 85$ & 22 & $49-4$ & $12 / 86$ \\
\hline 201 & $2 / 86$ & 10 & $49-4$ & $12 / 86$ \\
\hline 244 & $10 / 85$ & 14 & $49-4$ & $12 / 86$ \\
\hline 82 & $5 / 86$ & 9 & $50-1$ & $2 / 87$ \\
\hline 117 & $2 / 86$ & 12 & $50-1$ & $2 / 87$ \\
\hline 165 & $10 / 85$ & 16 & $50-1$ & $2 / 87$ \\
\hline 226 & $5 / 86$ & 9 & $50-1$ & $2 / 87$ \\
\hline 54 & $8 / 85$ & 19 & $50-2$ & $3 / 87$ \\
\hline 170 & $12 / 85$ & 15 & $50-2$ & $3 / 87$ \\
\hline 155 & $10 / 85$ & 19 & $50-4$ & $4 / 87$ \\
\hline 202 & $8 / 86$ & 8 & $50-4$ & $4 / 87$ \\
\hline 204 & $4 / 86$ & 12 & $50-4$ & $4 / 87$ \\
\hline 70 & $1 / 86$ & 16 & $51-1$ & $5 / 87$ \\
\hline 56 & $2 / 86$ & 16 & $51-1$ & $5 / 87$ \\
\hline 73 & $4 / 86$ & 13 & $51-1$ & $5 / 87$ \\
\hline 74 & $1 / 86$ & 17 & $51-2$ & $6 / 87$ \\
\hline 118 & $12 / 85$ & 18 & $51-2$ & $6 / 87$ \\
\hline 140 & $4 / 86$ & 14 & $51-2$ & $6 / 87$ \\
\hline 172 & $3 / 86$ & 18 & $51-4$ & $9 / 87$ \\
\hline 200 & $12 / 86$ & 9 & $51-4$ & $9 / 87$ \\
\hline 222 & $2 / 87$ & 7 & $51-4$ & $9 / 87$ \\
\hline 154 & $9 / 86$ & 12 & $52-1$ & 9/87 \\
\hline 180 & $12 / 86$ & 10 & $52-1$ & $9 / 87$ \\
\hline 136 & $9 / 86$ & 13 & $52-2$ & $10 / 87$ \\
\hline 166 & $4 / 85$ & 30 & $52-2$ & $10 / 87$ \\
\hline 135 & $10 / 86$ & 12 & $52-2$ & $10 / 87$ \\
\hline 115 & $12 / 86$ & 12 & $52-4$ & $12 / 87$ \\
\hline 183 & $11 / 86$ & 13 & $52-4$ & $12 / 87$ \\
\hline 218 & $4 / 87$ & 8 & $52-4$ & $12 / 87$ \\
\hline 120 & $5 / 86$ & 18 & $52-4$ & $12 / 87$ \\
\hline 71 & $3 / 87$ & 11 & $53-1$ & $2 / 88$ \\
\hline 106 & $2 / 87$ & 12 & $53-1$ & $2 / 88$ \\
\hline 138 & $12 / 86$ & 14 & $53-1$ & $2 / 88$ \\
\hline 168 & $2 / 87$ & 14 & $53-2$ & $4 / 88$ \\
\hline 199 & $4 / 87$ & 12 & $53-2$ & $4 / 88$ \\
\hline 159 & $10 / 86$ & 19 & $53-4$ & $5 / 88$ \\
\hline 238 & $5 / 87$ & 12 & $53-4$ & $5 / 88$ \\
\hline 88 & $9 / 87$ & 10 & $54-1$ & $6 / 88$ \\
\hline 93 & $5 / 86$ & 25 & $54-1$ & $6 / 88$ \\
\hline 178 & $5 / 87$ & 15 & $54-2$ & $8 / 88$ \\
\hline 182 & $5 / 87$ & 15 & $54-2$ & $8 / 88$ \\
\hline 86 & $12 / 87$ & 9 & $54-4$ & $9 / 88$ \\
\hline 173 & $10 / 87$ & 11 & $54-4$ & $9 / 88$ \\
\hline
\end{tabular}




\begin{tabular}{|c|c|c|c|c|}
\hline $\begin{array}{l}\text { A-Chain } \\
\text { Number }\end{array}$ & $\begin{array}{l}\text { Submitted } \\
\text { to NNDC }\end{array}$ & Months in Pipeline* & Issue & Publication Date \\
\hline 68 & $9 / 87$ & 13 & $55-1$ & $10 / 88$ \\
\hline 157 & $8 / 87$ & 14 & $55-1$ & $10 / 88$ \\
\hline 151 & $12 / 86$ & 22 & $55-2$ & $12 / 88$ \\
\hline 179 & $9 / 87$ & 15 & $55-4$ & $12 / 88$ \\
\hline 186 & $9 / 87$ & 15 & $55-4$ & $12 / 88$ \\
\hline 214 & $11 / 87$ & 13 & $55-4$ & $12 / 88$ \\
\hline 72 & $12 / 87$ & 14 & $56-1$ & $2 / 89$ \\
\hline 194 & $10 / 87$ & 16 & $56-1$ & $2 / 89$ \\
\hline 158 & $8 / 87$ & 19 & $56-2$ & $3 / 89$ \\
\hline 163 & $6 / 87$ & 21 & $56-2$ & $3 / 89$ \\
\hline 84 & $9 / 88$ & 7 & $56-4$ & $4 / 89$ \\
\hline 144 & $12 / 87$ & 16 & $56-4$ & $4 / 89$ \\
\hline 191 & $2 / 88$ & 14 & $56-4$ & $4 / 89$ \\
\hline 195 & $3 / 88$ & 15 & $57-1$ & $6 / 89$ \\
\hline 77 & $2 / 88$ & 18 & $57-3$ & $8 / 89$ \\
\hline 139 & $1 / 88$ & 19 & $57-3$ & $8 / 89$ \\
\hline 112 & $7 / 88$ & 15 & $57-4$ & $10 / 89$ \\
\hline $246-266(e)$ & $4 / 88$ & 18 & $57-4$ & $10 / 89$ \\
\hline 69 & $11 / 88$ & 12 & $58-1$ & $11 / 89$ \\
\hline 152 & $4 / 88$ & 20 & $58-1$ & $11 / 89$ \\
\hline 184 & $5 / 88$ & 19 & $58-1$ & $11 / 89$ \\
\hline 89 & $5 / 89$ & 6 & $58-2$ & $12 / 89$ \\
\hline 185 & $9 / 88$ & 15 & $58-2$ & $12 / 89$ \\
\hline 229 & $2 / 89$ & 10 & $58-2$ & $12 / 89$ \\
\hline 167 & $10 / 88$ & 15 & $58-4$ & $1 / 90$ \\
\hline 130 & $8 / 88$ & 17 & $58-4$ & $1 / 90$ \\
\hline 52 & $6 / 88$ & 19 & $58-4$ & $1 / 90$ \\
\hline 161 & $10 / 88$ & 18 & $59-1$ & $\therefore \quad 3 / 90$ \\
\hline 233 & $12 / 88$ & 15 & $59-1$ & $3 / 90$ \\
\hline 188 & $1 / 89$ & 14 & $59-1$ & $3 / 90$ \\
\hline $116(u)$ & $2 / 88$ & 27 & $59-2$ & $5 / 90$ \\
\hline 148 & $8 / 88$ & 21 & $59-2$ & $5 / 90$ \\
\hline $249-265(0)$ & $12 / 88$ & 17 & $59-2$ & $5 / 90$ \\
\hline $240(u)$ & $4 / 88$ & 25 & $59-4$ & $5 / 90$ \\
\hline $113(u)$ & $10 / 88$ & 20 & $59-4$ & $5 / 90$ \\
\hline 189 & $10 / 88$ & 20 & $59-4$ & $5 / 90$ \\
\hline 137 & $12 / 88$ & 17 & $59-4$ & $5 / 90$ \\
\hline 100 & $11 / 88$ & 20 & $60-1$ & $6 / 90$ \\
\hline 114 & $4 / 89$ & 14 & $60-1$ & $6 / 90$ \\
\hline 176 & $5 / 89$ & 14 & $60-1$ & $6 / 90$ \\
\hline $153(\mathrm{u})$ & $10 / 88$ & 23 & $60-2$ & $8 / 90$ \\
\hline 62 & $12 / 88$ & 20 & $60-2$ & $8 / 90$ \\
\hline 198 & $4 / 89$ & 16 & $60-2$ & $8 / 90$ \\
\hline
\end{tabular}




\begin{tabular}{|c|c|c|c|c|}
\hline $\begin{array}{l}\text { A-Chain } \\
\text { Number }\end{array}$ & $\begin{array}{l}\text { Submitted } \\
\text { to NNDC }\end{array}$ & Months in Pipeline* & Issue & Publication Date \\
\hline 225 & $7 / 89$ & 14 & $60-2$ & $8 / 90$ \\
\hline $146(u)$ & $10 / 88$ & 23 & $60-4$ & $9 / 90$ \\
\hline 111(u) & $3 / 89$ & 18 & $60-4$ & $9 / 90$ \\
\hline 91(u) & $8 / 89$ & 14 & $60-4$ & $9 / 90$ \\
\hline 75 & $1 / 89$ & 20 & $60-4$ & $9 / 90$ \\
\hline $50(u)$ & $12 / 89$ & 11 & $61-1$ & $11 / 90$ \\
\hline $53(\mathrm{u})$ & $12 / 89$ & 11 & $61-1$ & $11 / 90$ \\
\hline 206 & $8 / 89$ & 15 & $61-1$ & $11 / 90$ \\
\hline $58(\mathrm{u})$ & $3 / 89$ & 21 & $61-2$ & $12 / 90$ \\
\hline 190 & $12 / 89$ & 12 & $61-2$ & $12 / 90$ \\
\hline 193 & $9 / 89$ & 16 & $61-4$ & $12 / 90$ \\
\hline $66(u)$ & $12 / 89$ & 12 & $61-4$ & $12 / 90$ \\
\hline 221 & $8 / 90$ & 5 & $61-4$ & $12 / 90$ \\
\hline 174(u) & $12 / 89$ & 15 & $62-1$ & $3 / 91$ \\
\hline $181(\mathrm{u})$ & $12 / 89$ & 15 & $62-1$ & $3 / 91$ \\
\hline 187 & $10 / 89$ & 18 & $62-1$ & $3 / 91$ \\
\hline $85(u)$ & $4 / 89$ & 24 & $62-2$ & $4 / 91$ \\
\hline 87 & $8 / 89$ & 20 & $62-2$ & $4 / 91$ \\
\hline 197 & $12 / 89$ & 17 & $62-2$ & $4 / 91$ \\
\hline $64(u)$ & $5 / 90$ & 12 & $62-4$ & $5 / 91$ \\
\hline 107 & $12 / 89$ & 18 & $62-4$ & $5 / 91$ \\
\hline $108(u)$ & $10 / 89$ & 19 & $62-4$ & $5 / 91$ \\
\hline $78(\mathrm{u})$ & $7 / 90$ & 13 & $63-1$ & $7 / 91$ \\
\hline 211 & $10 / 90$ & 10 & $63-1$ & $7 / 91$ \\
\hline 232,236 & $5 / 90$ & 15 & $63-1$ & $7 / 91$ \\
\hline $51(u)$ & $11 / 90$ & 9 & $63-2$ & $8 / 91$ \\
\hline 101(u) & $10 / 90$ & 10 & $63-2$ & $8 / 91$ \\
\hline $102(\mathrm{u})$ & $9 / 90$ & 11 & $63-2$ & $8 / 91$ \\
\hline 217 & $2 / 91$ & 6 & $63-2$ & $8 / 91$ \\
\hline $141(u)$ & $12 / 89$ & 22 & $63-4$ & $10 / 91$ \\
\hline $142(u)$ & $8 / 89$ & 26 & $63-4$ & $10 / 91$ \\
\hline 209 & $10 / 90$ & 12 & $63-4$ & $10 / 91$ \\
\hline $104(u)$ & $6 / 90$ & 17 & $64-1$ & $11 / 91$ \\
\hline 162 & $5 / 90$ & 18 & $64-1$ & $11 / 91$ \\
\hline 192 & $1 / 91$ & 10 & $64-1$ & $11 / 91$ \\
\hline 121 & $9 / 90$ & 15 & $64-2$ & $12 / 91$ \\
\hline $143(u)$ & $3 / 90$ & 21 & $64-2$ & $12 / 91$ \\
\hline 169 & $6 / 90$ & 19 & $64-2$ & $12 / 91$ \\
\hline $55(u)$ & $12 / 90$ & 13 & $64-4$ & $1 / 92$ \\
\hline 63(u) & $5 / 91$ & 8 & $64-4$ & $1 / 92$ \\
\hline $67(\mathrm{u})$ & $12 / 90$ & 13 & $64-4$ & $1 / 92$ \\
\hline $109(u)$ & $9 / 90$ & 16 & $64-4$ & $1 / 92$ \\
\hline $45(\mathrm{u})$ & $9 / 90$ & & sent $t$ & ublisher \\
\hline
\end{tabular}




\begin{tabular}{|c|c|c|c|}
\hline $\begin{array}{l}\text { A-Chain } \\
\text { Number }\end{array}$ & $\begin{array}{l}\text { Submitted } \\
\text { to NNDC }\end{array}$ & Months in Pipeline* & Publication Date \\
\hline $\begin{array}{l}156(u) \\
210(u)\end{array}$ & $\begin{array}{l}6 / 91 \\
4 / 91\end{array}$ & & $\begin{array}{l}\text { sent to publisher } \\
\text { sent to publisher }\end{array}$ \\
\hline 147 & $12 / 88$ & & in pipeline \\
\hline 164 & $12 / 89$ & & in pipeline \\
\hline 175 & $8 / 90$ & & in pipeline \\
\hline 223 & $9 / 90$ & & in pipeline \\
\hline 227 & $9 / 90$ & & in pipeline \\
\hline 150 & $9 / 90$ & & in pipeline \\
\hline 183 & $9 / 90$ & & in pipeline \\
\hline 132 & $10 / 90$ & & in pipeline \\
\hline 145 & $10 / 90$ & & in pipeline \\
\hline 219 & $12 / 90$ & & in pipeline \\
\hline 92 & $12 / 90$ & & in pipeline \\
\hline 166 & $12 / 90$ & & in pipeline \\
\hline 165 & $12 / 90$ & & in pipeline \\
\hline 215 & $12 / 90$ & & in pipeline \\
\hline 90 & $4 / 91$ & & in pipeline \\
\hline 212 & $4 / 91$ & & in pipeline \\
\hline 213 & $7 / 91$ & & in pipeline \\
\hline 171 & $7 / 91$ & & in pipeline \\
\hline 244 & $7 / 91$ & & in pipeline \\
\hline 117 & $8 / 91$ & & in pipeline \\
\hline 59 & $8 / 91$ & & in pipeline \\
\hline 239 & $9 / 91$ & & in pipeline \\
\hline 247 & $9 / 91$ & & in pipeline \\
\hline 119 & $9 / 91$ & & in pipeline \\
\hline 57 & $9 / 91$ & & in pipeline \\
\hline 96 & 9/91 & & in pipeline \\
\hline 115 & $10 / 91$ & & in pipeline \\
\hline 83 & $11 / 91$ & - & in pipeline \\
\hline 94 & $11 / 91$ & & in pipeline \\
\hline 81 & $12 / 91$ & & in pipeline \\
\hline 160 & $12 / 91$ & & in pipeline \\
\hline 110 & $12 / 91$ & & in pipeline \\
\hline 80 & $12 / 91$ & & in pipeline \\
\hline 46 & $12 / 91$ & & in pipeline \\
\hline 48 & $12 / 91$ & & in pipeline \\
\hline
\end{tabular}

* Time to produce, edit, review, revise, and publish.
(e) Even-A only.
(o) Odd-A only.
(u) Update mode. 
TABLE 3 STATUS OF A-CHAINS NOT PRESENTED IN TABLE 2

\begin{tabular}{|c|c|c|c|c|}
\hline A-Chain & $\begin{array}{l}\text { Last Issue } \\
\text { (volume) }\end{array}$ & $\begin{array}{l}\text { Publication } \\
\text { Date }\end{array}$ & Assignment & $\begin{array}{l}\text { Being } \\
\text { Evaluated@ }\end{array}$ \\
\hline 61 & 38 & 1983 & Sweden§ & yes \\
\hline 76 & 42 & 1984 & Kuwait $§$ & (1992) \\
\hline 79 & 37 & 1982 & Kuwait§ & yes \\
\hline 95 & 38 & 1983 & BNL & yes \\
\hline 98 & 39 & 1983 & Canada & yes \\
\hline $123 \dagger$ & 29 & 1980 & Japan & no \\
\hline 124 & 41 & 1984 & Japan & no \\
\hline 125 & 32 & 1981 & Japan & yes \\
\hline 126 & 36 & 1982 & Japan & yes \\
\hline $127 \dagger$ & 35 & 1982 & Japan & no \\
\hline 128 & 38 & 1983 & Japan & yes \\
\hline 129 & 39 & 1983 & Japan & yes \\
\hline $131^{*}$ & 17 & 1976 & USSR & yes \\
\hline 134 & 34 & 1981 & USSR & yes \\
\hline $177^{*}$ & 16 & 1975 & LBL & yes \\
\hline $196^{*}$ & 28 & 1979 & China & yes \\
\hline 230 & 40 & 1983 & NDP & (1992) \\
\hline 231 & 40 & 1983 & NDP & yes \\
\hline 234 & 40 & 1983 & NDP & (1992) \\
\hline 235 & 40 & 1983 & NDP & yes \\
\hline 243 & 33 & 1981 & NDP & yes \\
\hline 245 & 33 & 1981 & NDP & (1992) \\
\hline
\end{tabular}

(1) Tentative completion dates are indicated, if available.

$\S$ Evaluation has been temporarily assigned to another data center.

$\dagger$ Status of this A-chain has not changed since 1990 report.

- Status of this A-chain has not changed since 1989 report: the A-chain is still being evaluated. 
TABLE 4 CONTINUOUS EVALUATIONS OF NUCLEAR STRUCTURE DATA

\begin{tabular}{lll}
\hline A-Chain & Center & Year Completed \\
\hline 50 & BNL & 1991 \\
66 & BNL & 1991 \\
116 & France & 1991 \\
181 & LBL & 1991 \\
187 & LBL & 1991 \\
189 & LBL & 1991 \\
\hline
\end{tabular}

\section{U.S. Data Centers}

The responsibility for evaluating light nuclides from $A=3-20$ is now assigned to the Triangle Universities Nuclear Laboratory (TUNL). In 1991, the evaluation of $A=4$ was completed and was submitted for publication in Nuclear Physics; publication is expected in early 19.92. The transfer of evaluation resources from Prof. Ajzenberg-Selove at the University of Pennsylvania to TUNL is now complete. The next $A$-chains to be evaluated are $A=16$ and 17. TUNL personnel are also learning procedures for evaluating A-chains in the ENSDF format, by visiting Brookhaven and working with Dr. Mulki Bhat on entering the earlier compilations into ENSDF. Although the TUNL group is not currently on schedule for producing the first evaluation in its new assignment, the panel does recognize that such a transition can be more difficult than originally contemplated, and anticipates that the timely production of evaluations of the light nuclei will soon return to the 5-year cycle time that Prof. Ajzenberg-Selove maintained. In particular, the TUNL group anticipates that a preprint on $A=16$ will be available by the middle of 1992 .

The Idaho Nuclear Engineering Laboratory (INEL) has responsibility for evaluating A-chains in the region $A=153-163$. Recently, the $A=87 \mathrm{~A}$-chain, formerly handled by the Karlsruhe group in Germany, was assigned to INEL as an additional permanent responsibility. In 1991, INEL submitted for publication two mass chains, $A=156$ and 160 . No continuous evaluations were completed. The A-chain evaluation for $A=162$ has been published. With the decentralization of review responsibilities, INEL has reviewed four A-chain evaluations this year. With two evaluators for a total of $0.8 \mathrm{FTE}$, the productivity of this group is approximately 2.5 evaluations per FTE per year.

The Lawrence Berkeley Laboratory (LBL) Isotopes Project has been responsible for evaluating 33 mass chains, including $A=89-93$ and $A=167-194$, and for converting $A=33-44$ into ENSDF format. Temporary responsibility has been assigned to LBL for $A=81$ and 83 (from the Nuclear Data Project at ORNL), $A=76,79$, and 80 (from the Nuclear Data Project in Kuwait), and $A=59$ (from the Swedish group at Lund). In addition, permanent responsibility was recently assigned to LBL for 206, 210-212, 215, 219, 223, and 227; LBL's current permanent assignment is now 41 A-chains. In 1991 the Isotopes Project submitted seven evaluations $(A=59,80,81,83,171,192$, and 210). Five $A$-chains were published $(A=169,174,181,187$, and 192). Three continuous evaluations $(A=181,187$, and 189$)$ were completed. In addition, five mass-chain evaluations were reviewed, including two from late last year. The effort level is 2.5 FTE, which means that the average output is about $2.8 \mathrm{~A}$-chains per FTE per year. The panel is pleased that LBL has accepted many additional A-chain assignments and has maintained a high level of productivity of evaluations, since their effort is also occupied with production of the Table of Isotopes. 
The Oak Ridge National Laboratory (ORNL) Nuclear Data Project (NDP) is now responsible for $A=81-85$ and for mass chains with $A=200-205,207-209,213,214,216-218,220-222,224-226$, 228-237, 239, 241, 243, and 245-266. Responsibility for $A=81$ and 83 has temporarily been given to LBL, $A=82$ to Russia, and $A=211-212$ to Brookhaven. Although some of the heavier A-chains take less work than do lighter A-chains, the NDP is still responsible for at least 40 effective A-chains. In 1991 this group submitted four evaluations $(A=213,217,239$, and 247), and four mass chains $(A=209,217,232$, and 236$)$ have been published. In addition, 14 evaluations were reviewed. The number of evaluators is $1.5 \mathrm{FTE}$, for an average productivity in 1991 of 2.7 A-chains per FTE per year. This is an improvement over past years and may reflect the success of decentralizing the review process so that the ORNL group can spend more time on evaluation. However, the cycle time for 40 effective A-chains would be about 8 years at a rate of 5 effective A-chain evaluations per year. For a center with currently only 1.5 FTE evaluators and 40 A-chains, too many of the A-chains assigned to the NDP are, not surprisingly, severely out of date. In the short term every effort should be made to assign, at least on a temporary basis, the most out-of-date A-chains. However, in the long term the historical responsibility of this center should be reexamined, to reflect better the current distribution of evaluators in the U.S. Network.

The National Nuclear Data Center (NNDC) at Brookhaven National Laboratory (BNL) is responsible for $A=45-50,57,58,65-73,94-97,99,136-148,150,152,165$ and 199. In addition the NNDC has assumed temporary responsibility for $A=211$ and 212 from the Nuclear Data Project at ORNL. In 1991 the NNDC submitted 7 -chain evaluations $(A=46,48,57,94,95,96$, and 212), 4 evaluations were published $(A=211,141,142$, and 143$)$, and one is in press $(A=45)$. Continuous evaluations of $A=50$ and 66 were completed. All of their evaluations have been brought up to current standards. The NNDC also reviewed 11 evaluations. With 2.75 FTE evaluators, the productivity is approximately 1.8 evaluations per FTE per year; this is the lowest productivity of any U.S. center and is especially discouraging given the experience of the NNDC evaluators.

The panel notes that in nearly every U.S. data center the evaluation output is now about 2.5 A-chains per FTE per year. It also notes that review responsibilities have been accepted by all of these centers. Thus the output per evaluator seems to have increased. One factor that the panel does not know how to assess is that some evaluations are being carried out in update mode with, presumably, some reduction in the amount of work required. Also, most of the evaluations are already in ENSDF format, so that entering new or revised data is easier. To shorten the cycle time for A-chains toward the 5-year target, even greater productivity will be required from each evaluator. However, at least for the short term, the panel strongly recommends that the number of FTE evaluators in the United States not decrease.

The assignment of A-chains to centers has been historic. Redistribution of resources between the U.S. centers has occurred over the past-years, arid this has also affected the number of FTE evaluators associated with each center. The panel recommends that the U.S. Network be flexible in the assignment of A-chains to individual centers (and evaluators) and as a group concentrate on evaluating those A-chains that are the most outdated, irrespective of which center has traditionally had that responsibility.

\section{Foreign Data Centers}

Foreign centers contributed 11 of the 31 A-chains submitted for publication in 1990. In 1991, 7 of the 26 evaluations that were submitted came from foreign centers. Thus the foreign contribution to the Network continues to be significant. The evaluations received came from France (2), Russia, Sweden, Taiwan, Belgium, and Japan. The panel is especially pleased to learn about the high productivity of the French effort. With 0.5 FTE the French center was able to 
Figure 1 Status of A-chains in ENSDF as a function of literature cut-off date.

\section{A-Chain Status in ENSDF ( $A>44)$ \\ Center - ALL \\ 11-FEB-92}

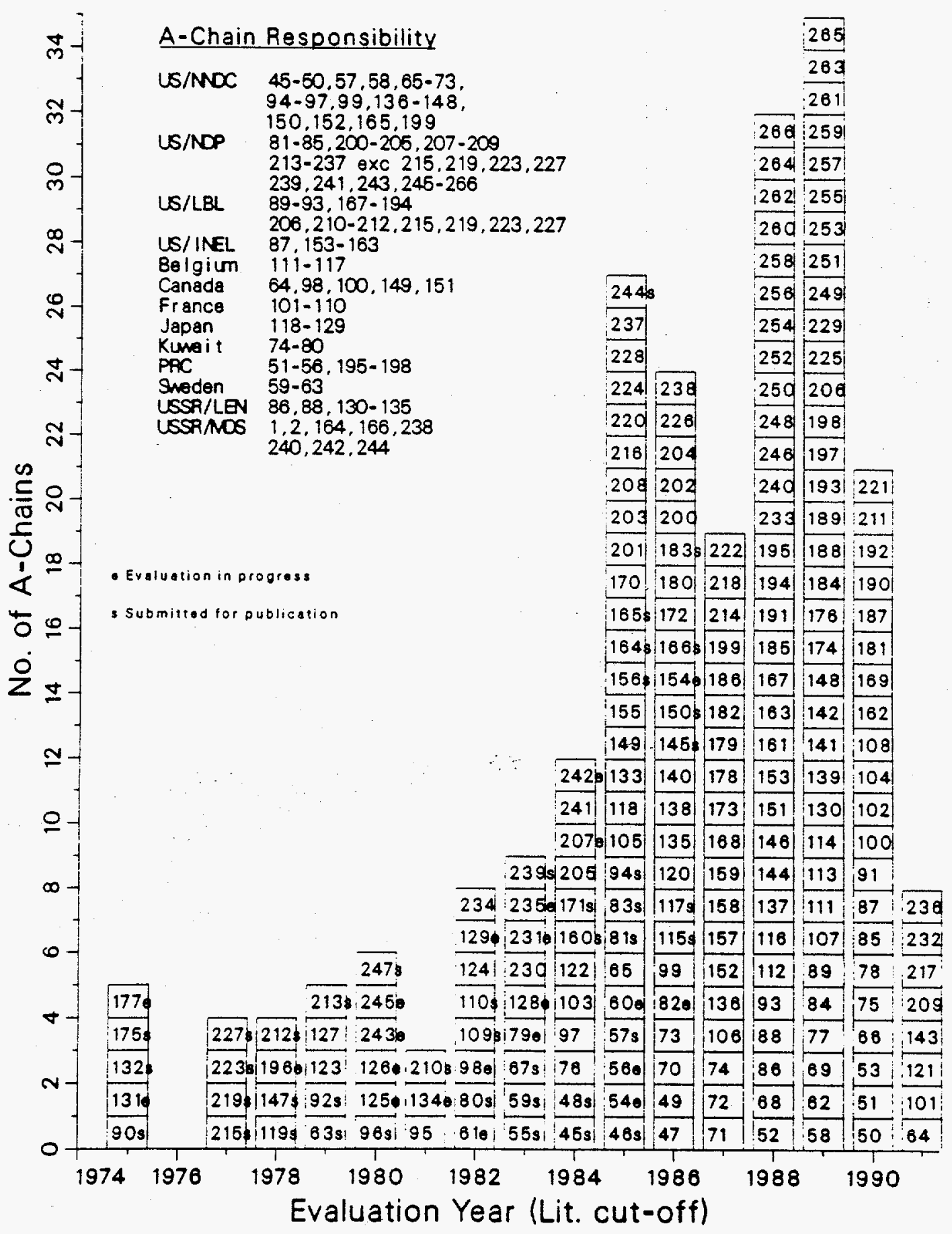




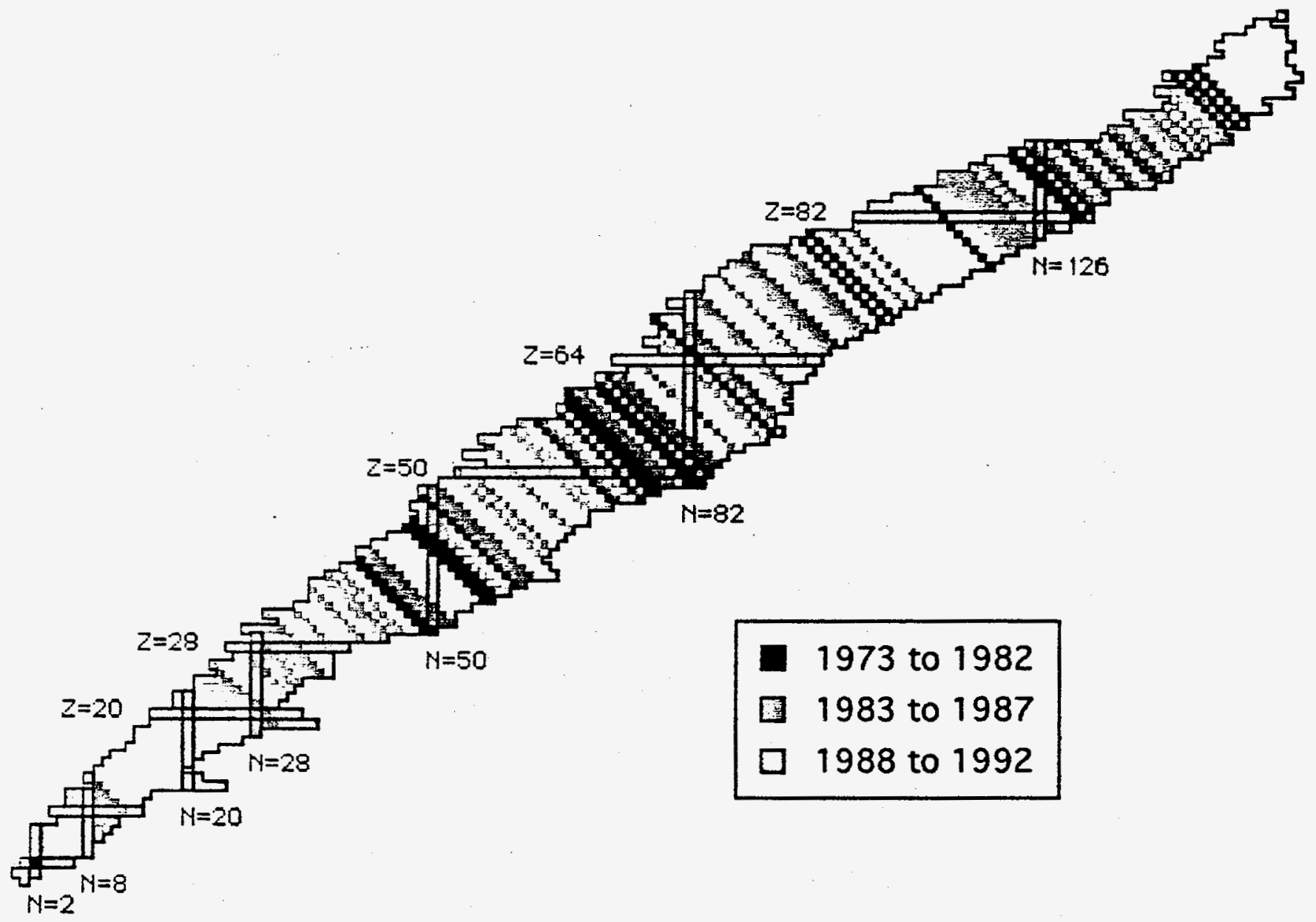

Figure 2. Status of the A-chains as a function of publication date.

Current A-chains are indicated in yellow; dated A-chains are in blue and black. This figure was provided by Prof. C.A. Stone using his MacNuclide program. 
submit two evaluations and one continuous evaluation in 1991. This high level of productivity (4.0 evaluations per FTE per year) should provide a goal for all of the U.S. centers.

The panel was also pleased to learn that a new evaluation of $A=21-44$ was published in early 1991. Although Prof. Van der Leun has retired, Prof. Endt plans to continue his efforts in this mass region for another evaluation cycle. The panel hopes that the International Network can work with Prof. Endt so that a qualified successor can be identified to maintain the evaluation efforts in this mass region on a timely schedule over the long run.

The transfer of responsibility for A-chain evaluations continues due to a variety of factors. The foreign centers show themselves to be just as vulnerable to funding and priority changes as are. U.S. centers. In the past year, the evaluations at Lund for $A=59-63$ were temporarily transferred to LBL $(A=59)$, Taiwan $(A=60,62$ and 63$)$, and China $(A=61)$. Because of the destruction of the center in Kuwait, the responsibility for $A=76,79$, and 80 was transferred temporarily to LBL. The

panel was very happy to learn that the Kuwaiti center is being rebuilt and plans to restart its evaluation work within the next two years.

A continuing problem with evaluations assigned to Japan was noted by the panel. Promises from Japan were reported for better output in the near future. If these promises are not fulfilled, then the panel urges the Network to reassign responsibility for the A-chains to centers that have a commitment to carry out the work. While the Japanese did complete one evaluation in 1991, the status of the Japanese responsibility needs to be reexamined, because at present the average A-chain for which the Japanese have responsibility is approximately 9 years old. This is especially critical with the expectation that production of the Table of Isotopes will begin in early 1993. The panel was pleased to learn that $A \doteq 177$, which the Japanese had assumed as a temporary responsibility, has been returned to $L B L$, which is doing this evaluation.

The cessation of participation in the Network by certain developed countries such as the United Kingdom and Germany was again noted and deplored by the panel. The panel suggests that the reasons for this secession be studied to determine if it is due to internal priorities or to foreign dissatisfaction with the content, quality, or usefulness of the A-chain evaluations. If it is the latter, then discussion with the appropriate foreign centers may result in suggestions for improvements in the evaluation process.

The possibility of evaluation work being done in Eastern Europe was reported to the panel. In particular, Hungary has expressed interest in joining the Network. The panel very much welcomed this news and encourages the Network to explore with other Eastern European centers the possibility of participating in the evaluations. These centers are home to experienced nuclear scientists and they are near the International Atomic Energy Agency (IAEA) headquarters in Vienna, where training in evaluations can be easily carried out. It may also be appropriate to identify nuclear scientists in the former USSR who could work with the international Network with financial support from both the U.S. and foreign governments.

The panel repeats the position of the International Nuclear Data Committee (1984) that "the IAEA should use all the ways and means at its disposal to try to eliminate the serious problem in maintaining the target production schedule of mass evaluations. Steps to be taken should include bringing the problem to the attention of governments and national nuclear energy organs, and sending letters of appreciation to evaluators when their work is accepted for publication."

\section{PRODUCTION PIPELINE}

In 1991 only 26 evaluations were submitted to the production pipeline, fewer than in previous years and a number far short of the approximately 36 A-chains per year that could be processed with the current facility at NNDC. Nineteen of these evaluations were submitted by the 7.5 FTE U.S. evaluators, which is exactly 2.5 A-chains per FTE per year. Also 6 continuous evaluations were submitted, which means that 32 out of 266 A-chains will soon be updated in ENSDF. 
The number of A-chains entering the pipeline directly affects the number that will be published in the next year. Currently there are $35 \mathrm{~A}$-chains in the production pipeline. The panel does not anticipate that the number of A-chains that, in principle, could be published in 1992 will be less than could be accommodated by the number of pages allowed by the publisher of Nuclear Data Sheets. However, the panel recommends that the productivity of individual evaluators, individual centers, and the U.S. Network as a whole be reexamined so that as many evaluations as possible can be submitted each year, either as complete evaluations, or in update or continuous formats.

The production pipeline itself continues to be a major bottleneck in the timely issuance of A-chain evaluations. The situation is deteriorating with time, despite apparent attempts to ameliorate it. The average elapsed time from A-chain submission to publication is summarized in Table 5. A plot of these times is given in Figure 3.

Despite the decrease in production time in 1991, the trend is clearly upward and belies any claims that progress is being made toward the goal of a 12-month production period. Indeed, extrapolation of the trend line reaches nearly a 22 -month average by the turn of the century. This is particularly disturbing in view of the efficiencies that would have been expected attendant upon the increased use of computer control and manipulation during the process, the use of express mail, and the distribution of review duties throughout the International Network.

If the goal of a reasonably up-to-date A-chain database is to be achieved, this overall trend must be reversed, and must be reversed rapidly. To do so, the prime bottlenecks need to be better identified. There are basically five steps in the evaluation process: the processing time needed for an A-chain at the NNDC (which actually consists of the sum of times for several passthroughs), the review process, the evaluator response to review, final editing by the editor-in-chief, and actual publication. The last two steps are short (together they average 2.1 months), and it is hard to see further efficiencies here. Also, time spent at the publisher before actual publication does not affect the currency of the data available via on-line access. Therefore, the time savings must come in the first three steps, which took, on average, 4.0, 3.8, and 5.3 months, respectively, in 1991. Moreover, each step shows large scatter in individual elapsed times. For example, the NNDC stage varied from 1.8 to 8.0 months, the review process from 1.4 to as high as 13.7 months, and the evaluator response time from 1.2 to 12.2 months. The short times here indicate that these stages can be accomplished quickly but typically are not. While there has been significant improvement in the past year in the time spent at NNDC and some improvement in the time spent with the evaluator, the time spent in review has continued to increase, in spite of the redistribution of the review responsibilities throughout the international network.

How can reductions in time be achieved? Three aspects of the process were uncovered by the panel that may give some clues.

The first is that the original evaluations are often of rather poor quality. A study made by the NNDC of sample reviews of A-chains found a staggering, approximately 350 comments per A-chain on average. These comments do not necessarily represent errors, since a reviewer could be wrong in some cases, but they indicate either errors or situations in which the procedures and standards are not sufficiently established, with the result that two evaluators (original evaluator and reviewer who is also an evaluator) can inspect the same data and papers and reach opposite conclusions. The most disturbing aspect of so great a lack of agreement is that, invariably, most of the information in a given A-chain is not, in fact, new. Therefore, the 350 comments either center on only a fraction of the content of the A-chain, or new errors are introduced into old data by the process itself. Each scenario is disheartening. 
TABLE 5 NUCLEAR DATA SHEETS PROCESSING STATISTICS FOR 1985-1991*

\begin{tabular}{llllllll}
\hline Year & $\begin{array}{l}\text { No. of } \\
\text { A-chains }\end{array}$ & NNDC & Evaluator & Review & $\begin{array}{l}\text { Editor- } \\
\text { in-Chief }\end{array}$ & Publisher & Total \\
\hline 1985 & 22 & 4.4 & 2.7 & 2.2 & 0.4 & 2.2 & 11.8 \\
1986 & 22 & 5.2 & 3.6 & 2.8 & 1.0 & 2.2 & 14.7 \\
1987 & 27 & 4.6 & 3.3 & 3.4 & 0.5 & 2.1 & 13.9 \\
1988 & 19 & 3.8 & 3.7 & 3.6 & 0.8 & 2.5 & 14.4 \\
1989 & 21 & 4.5 & 3.7 & 4.4 & 0.6 & 2.2 & 15.5 \\
1990 & 29 & 5.2 & 4.5 & 4.9 & 0.7 & 1.7 & 17.0 \\
1991 & 29 & 4.0 & 3.8 & 5.3 & 0.5 & 1.6 & 15.2 \\
& & & & & & & 12.0 \\
\hline
\end{tabular}

*These statistics reflect the time in months for the various stages in the pipeline:

NNDC time is for:

Preparation of pre-review

Preparation of review

Preparation of galley

Preparation of final

Evaluator time is for:

Evalua:or pre-review

Evaluator post-review

Review is the time for review by the reviewer

Editor-in-chief is the review time with the editor-in-chief

Publisher is the time needed by the publisher to produce the firal copy until the issue appears on the library shelf.

Particularly disturbing in all of this is the nature of the errors, as summarized in the NNDC memo: 13 percent were classified as due to evaluator judgement, 19 percent to $J^{\pi}$ values or arguments, 11 percent to transcription or proofreading errors, and 12 percent to style and format problems. Together these constitute 55 percent of the errors. The last two would seem to be easy to eliminate simply by establishing more clearly spelled out style guidelines. The other three are all one form or another of mistake or simple carelessness. The 19 percent value for $\mathrm{J}^{\pi}$ arguments is especially perplexing, since there do exist rather explicit guidelines here. Are these simply careless errors? Again, the magnitude of the problem really becomes apparent when it is realized that the vast majority of $\mathrm{J}^{\pi}$ values does not change from one evaluation of an $\mathrm{A}$-chain to the next in time. Nearly 70 errors in each A-chain (19 percent of 350 "errors" per chain) cannot in any sense be considered acceptable. 
Figure 3 Nuclear Data Sheets production pipeline 1985 to present.

\section{NDS Production Pipeline}

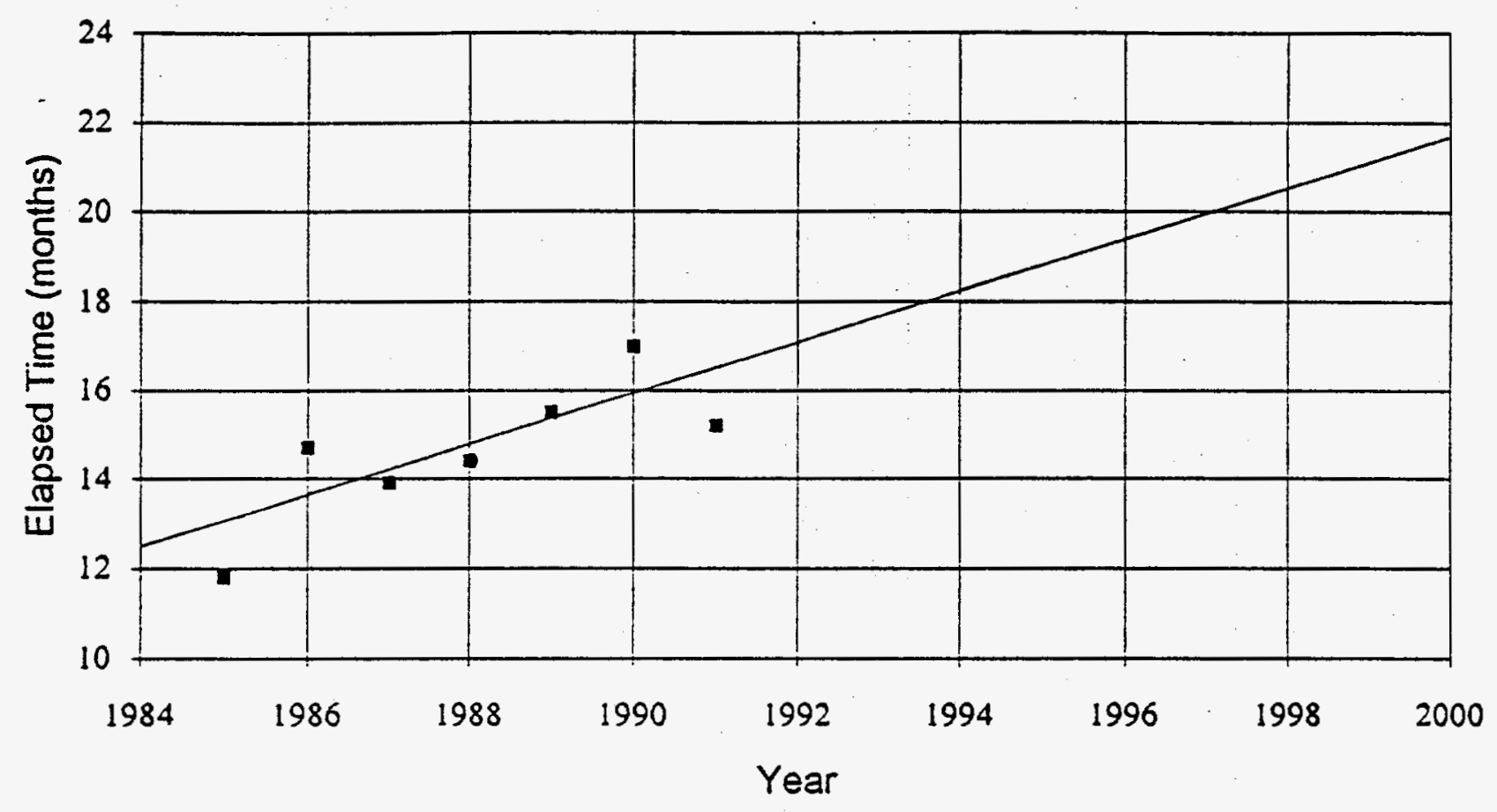


The only solution, of course, is to plead for more careful work by the evaluators or for more careful evaluators (or possibly more careful reviews, if the errors lie there instead). This will not happen merely by hoping for it.

To the extent that many of the errors are careless mistakes and, when pointed out, are immediately recognized as such, the advantages of internal review by an evaluator at the same institution become apparent. Simple one-on-one contact should then quickly settle well over half the errors. This approach was recommended for a trial in last year's report, but this suggestion was heeded only in a minimal way, and therefore no real "data" on its success and efficiency are available. The panel, therefore, strongly urges the immediate institution of internal review on a widespread test basis to assess how efficient it might be in increasing the accuracy of evaluations and thus reducing the time in review.

The second issue relating to pipeline efficiency is the priority given to different steps by the same person. A given evaluator will, during the year, attend to several tasks: evaluations (the primary responsibility), response to review, review of other A-chains, pre-review of copy, and proofreading of galleys. Evaluators, it seems, often favor the evaluation process because it is their primary work, even though an evaluation may take many months (even if worked on continuously), whereas some of the other stages may take only a couple of days or even less time.

The third and related issue, then, is that a submitted A-chain often sits on a desk or in a file for lengthy periods while other tasks are done. It has, in fact, become the case that as much as half of the total elapsed time for an A-chain in the pipeline may consist of downtime before the next step. This problem simply must be eradicated.

One possible solution is to establish (and require compliance with) a sort of algorithm defining priorities. Such an algorithm can be phrased: At any time, do the action that minimizes the number of A-chains at a given point in the process (i.e., on a given person's desk). In practice, this generally means dealing first with those A-chains closest to publication. Generally, the priority order is the following: proofreading galleys, response to referees, review of other A-chains, pre-review work, and evaluation.

Note that this order of priorities is exactly opposite both to the apparent tendency of most evaluators and to their predilections, since evaluation, the slowest and furthest step from publication, is generally their forte and their prime interest. Nevertheless, enforcement of the algorithm may significantly reduce the cvaluation downtime. It is far better to let an evaluation "lie fallow" for a few days or even a couple of weeks while galley proofs are read or a reviewer is answered or an evaluation is reviewed, than to put off these steps for many months while a different A-chain is evaluated. This algorithm applies both to evaluators and to the processing of A-chains at the NNDC. Combining use of the algorithm with internal review should result in a major reduction in the time spent on steps of the process that together required on average 9 months in 1991. The NNDC should also reexamine the steps that need to be taken to prepare an evaluation for dissemination either via publication in Nuclear Data Sheets and/or electronically, for example, via on-line access. Steps currently being taken are discussed further in Chapter 4 .

Finally, the panel notes that it is particularly critical to alleviate rapidly the bottlenecks in the pipeline so as to establish as much currency as possible in the A-chains in light of the upcoming publication of a new edition of the Table of Isotopes.

\section{NEW FORMATS}

In the last few years several new ideas have been suggested by both the panel and evaluators that have resulted in substantial change in the publication of evaluated A-chains. As noted in previous reports, the number of pages allocated to the publishing of Nuclear Data Sheets by Academic Press is close to the limit needed for the number of mass chains available for publication each year. Perhaps it would be possible to take the pages currently being used to publish the recent reference issues and redeploy them to A-chain publication. These issues are typically 70 
pages long, and there are three of them per year. The availability of worldwide access to the Nuclear Structure References (NSR) needs to be assessed before the step of eliminating recent references is taken.

In 1986 a new publishing format was adopted to reduce the blank space on a page, and it was projected that the average length of a published A'chain would shrink from 100 to 75 pages. The use of an update mode of publication was adopted on a trial basis in 1988. A given A-chain would be published once in an update mode before publication of a complete evaluation. It was projected that an update would be about 45 published pages versus 100 pages for a typical A-chain evaluation. In 1990 it was further proposed that once an A-chain was evaluated it would be continuously updated and so result in an annual update of every A-chain. The published version of this continuous update would be a brief report that would consist of a listing of new data and the relevant references.

A review of the published A-chains for 1991 shows about an equal split between publication in the update mode and normal publication. Full A-chain publications ranged in length from 35 to 132 pages, while update publications ranged from 37 to 106 pages. It is difficult to judge whether the update mode is saving published pages without knowing the extent of the new data. It appears that for nuclei with current activity the published update has about three-quarters the number of pages of a full evaluation.

In addition to a complete evaluation of an A-chain, which would be published either in its entirety or in update format, continuous evaluations of mass chains are also being done. It was decided by the Procedures and Format Committee of the USNDN not to publish a brief report for an A-chain that undergoes a continuous update, but rather to flag the A-chain in the Cumulated Index of A-chains published in the Nuclear Data Sheets; data that had been updated would be accessible on line. Six A-chains were submitted as a continuous update in 1991. A concern expressed by the evaluators was how a continuous evaluation would be counted in assessing their productivity. One measure could be to encourage each center to minimize the number of A-chains with a literature cut-off date more than 5 years old, normalized to the total number of A-chains in their assignment and the number of FTE evaluators. The productivity would be greatest when this normalized number is as small as possible. This measure would also discourage the reevaluation of an A-chain done simply to indicate a high level of productivity, and would instead emphasize the need to address severely outdated evaluations.

The impending publication of a new Table of Isotopes makes essential the conversion of the data files for $A<45$ into the ENSDF format. The NNDC at Brookhaven has completed $A=5-10$ and is currently coding $A=11$ and 12 . The NDP at ORNL is coding $A=13-26$, the effort at Grenoble for $A=27-32$ has been completed, and $A=33-44$ at LBL is in progress. All groups are optimistic that the project will be completed by the middle of 1992 .

\section{ON-LINE ACCESS}

On-line access to the NNDC databases increased dramatically in 1991, its sixth year of operation (Table 6). The on-line retrievals demonstrated a 87 percent growth in 1991 over 1990; access, in general, has almost doubled for all of the nuclear structure data and reference bases. This growth far exceeds the 44 percent growth in 1990 over 1989 and clearly indicates that important user needs are being satisfied by this form of rapid and convenient access to nuclear data and nuclear science information. With these growth rates, it is reasonable to conclude that there is a potential for further substantial growth in usage as the on-line system evolves to accommodate additional databases and as the NNDC staff develops improved video formats for enhanced utility and user-friendliness. 
TABLE 6 ON-LINE ACCESS TO NNDC DATABASES

\begin{tabular}{|c|c|c|c|c|c|c|c|c|c|c|c|}
\hline Year & Runs & Retrievals* & NSR & ENSDF & NUDAT & CINDA & CSISRS & ENDF & MIRD & PLOT & PHYSCO \\
\hline 1986 & 648 & 1621 & 814 & 142 & 536 & 129 & - & - & - & - & - \\
\hline 1987 & 1275 & 4263 & 2521 & 863 & 815 & 60 & - & 4 & - & - & - \\
\hline 1988 & 2264 & 8748 & 5022 & 1303 & 1492 & 285 & 459 & 187 & - & - & - \\
\hline 1989 & 3374 & 8406 & 3253 & 850 & 1841 & 522 & 1649 & 150 & - & - & - \\
\hline 1990 & 5436 & 12067 & 5613 & 1256 & 2204 & 187 & 1623 & 1019 & 53 & 39 & 65 \\
\hline 1991 & 10142 & 22183 & 11517 & 2807 & 4021 & 371 & 1384 & 1525 & 40 & 69 & 172 \\
\hline
\end{tabular}

*The number of pieces of information in each retrieval varies depending on the complexity of the retrieval. 
The database modules currently available on line are the NSR (Nuclear Structure References), NUDAT (Nuclear Data File), ENSDF (Evaluated Nuclear Structure Data File), CINDA (Neutron Reaction Bibliography), ENDF (Evaluated Nuclear Data File), CSISRS (Nuclear Reaction Data), and MIRD (Medical Internal Radiation Dose). During the past year a photoatomic database was added as X-RAY. In addition, the NNDC provides on-line access to selected software modules that allow users to do standard nuclear physics calculations of, e.g., internal conversion coefficients or log $f t$ values.

The panel is pleased to note that all retrieval programs are now accessible through video formats. Another noteworthy improvement during this past year is the implementation of a self-sign-up mechanism where by a first-time user can perform retrievals with the first login and the NNDC staff gives approval at a later stage. The development of a comprehensive user document has been initiated and is to be encouraged. It will be especially useful if the user document is available on line, as well, for searching and browsing. A next logical step in the evolution of the on line access system will be the development of a tutorial. It will be especially worthwhile if this tutorial has a beginner, an intermediate, and an advanced mode.

Mass-chain evaluations that are currently in review or in post-review status are now available on line so that the evaluated data file for a mass chain can be retrieved up to a year before it appears in print. The proposal of the NNDC to form a new database, XNSDF (Experimental Nuclear Structure Data File), of experimental data that has not been evaluated but is extremely topical, is highly encouraged. The NNDC could also serve to provide other databases that might be of use to the community.

A more difficult task for the NNDC is to determine future directions for developing software that allows users to manipulate the databases. There is a strong need for horizontal compilations, especially in areas of research that are experiencing tremendous growth in new data. The panel suggests regular meetings between users of the data and those maintaining the data. Perhaps a meeting to determine future directions of the database management system could be held at an upcoming fall meeting of The American Physical Society's Division of Nuclear Physics, or in conjunction with a topical conference in an area of intense research activity.

The panel strongly supports the continued development of on-line access databases and standardized software as well as the development of on-line documentation and tutorials.

It is evident to the panel that on-line access is the core of an eventual system of full electronic access to all nuclear data, standardized software, and nuclear science publications. Chapter 4 of this report addresses the corollary issues of electronic publication and dissemination.

\section{TABLE OF ISOTOPES}

The progress report by Dr. Richard B. Firestone of LBL indicates that the production of the 8th edition of the Table of Isotopes is on schedule. A sample page layout was presented that contained an amazing amount of data in a reasonably comprehensible style. A new addition to this edition will be the inclusion of rotational band drawings. The Nuclear Data Sheets reference for each nucleus for $A>45$ is shown on the first page of a given mass. Several evaluators have complained that their efforts were never acknowledged or mentioned in the 7 th edition of the Table of Isotopes. It is suggested that at a minimum the author's name be included in the Nuclear Data Sheets reference. The panel continues to support enthusiastically the Table of Isotopes project and is impressed with its rapid progress.

Dr. Firestone presented ideas for distributing the Table of Isotopes in media suitable for computer access. His proposal to continuously update the information in the Table of Isotopes will result in an enormously useful database that will allow easy access to quantities used for interpretation of nuclear properties as a function of mass, proton number, and so on. The combination of MacNuclide and the Table of Isotopes database should make nuclear structure comparisons extremely versatile. 
The panel urges the NNDC and LBL groups to work together to make the ENSDF files that will be generated to produce the Table of Isotopes as easily available electronically as are the existing databases residing at the NNDC.

\section{SUPPORT FOR BASIC NUCLEAR DATA EVALUATION ACTIVITIES}

The panel recognizes that the federal government is in a period of fiscal restraint; the funding in many areas of research is at near constant levels. The budgets at the nuclear data evaluation centers are essentially the salaries of the evaluators; these funds cannot be reduced without the loss of an evaluator. The panel believes strongly that the overall productivity of the U.S. evaluation effort cannot be allowed to decrease. This means that the number of evaluators in the United States cannot be less than the 7.5 FTE in 1991. That new evaluators have entered the U.S. effort as consultants is a cost-effective means of enlarging the evaluator pool. The panel hopes that these consultants continue to receive the support and benefits appropriate for their professional responsibilities. The panel also hopes that the production aspects of the data evaluation can be made as cost-effective as possible and, in particular, encourages the Nuclear Data Sheets production center at BNL and the Table of Isotopes production group at LBL to be as innovative as possible to maximize the cost-effectiveness of their operations.

The panel continues to believe that nuclear data evaluation is a vital effort that provides an essential database for basic and applied research, education, and a broad range of applications, including energy technologies, defense, cleanup and protection of the environment, biomedicine, geology, and space exploration. Benefits from this database are shared by countries around the world, and the United States makes more use of it than any other single country. This effort cannot survive indefinitely with flat budgets, especially since a large fraction of the support is for the salaries of the evaluators. The panel appreciates the Department of Energy's recognition of the importance of nuclear data evaluations and hopes that future commitments will be adequate to continue the high quality and efficiency of the U.S. efforts.

One of the issues addressed by the panel concerns the c"rrent needs of users of nuclear structure data. In particular, the needs of the high-spin nuclear spectroscopy community will soon be critical, given the explosion of new data with the advent of very large arrays of high-resol-ation gamma-ray detectors. One suggestion is to expand the evaluation effort by including scier.ists from this area of research, which is one way of bringing additional resources into the evaluation process. It may also be possible to convince the United Kingdom to rejoin the International Network, because of its heavy involvement in nuclear spectroscopy. Other sources of support can probably be identified, since many of the users are involved in applied research and development. The panel encourages the Department of Energy to be innovative in finding the resources necessary to maintain, and in the longer term expand, the network for evaluating and disseminating nuclear structure data. 



\section{4 \\ Future Directions in Nuclear Data Evaluations}

\section{ELECTRONIC PUBLICATION AND DISSEMINATION}

The panel is convinced that it cannot overemphasize the need for electronic publication and dissemination of evaluated nuclear data, as well as of nuclear data published prior to full evaluation. As electronic processing of information has grown to encompass all phases of research, from data acquisition through analysis to manuscript generation and even, in some preliminary stages, to electronic publication, it is natural to forecast the eventual development of full electronic publication and dissemination of research results and publications. The path to electronic publication and dissemination has been studied extensively by the Task Force on Electronic Information Systems of the American Physical Society and has been reported on recently in the Bulletin of The American Physical Society (Series II, Vol. 36, page 1119, 1991). While full implementation may require 10 to 20 years, this panel believes that a continuous serious effort focused on electronic publication will bring major improvements in the efficiency and accuracy of evaluators of nuclear data, as well as increase the utility of these data to researchers even in the short term.

The overall goal of the electronic publication and dissemination efforts should be to reduce the interval between the point when the researchers have completed their data analysis for publication and the point when those same data are evaluated and available to other researchers in a convenient medium. Increasingly, the preferred medium is electronic. In addition, there is great value in having the data available electronically, even prior to full evaluation, provided it is so labeled. In cases of great current research interest, such as high-spin properties of nuclei or properties of nuclei far off stability, electronic access to data prior to publication can be important. The panel heard progress reports and outlines of proposals from the NNDC anc' from LBL on the subjects of electronic publication and dissemination. The proposal outlines were too preliminary to allow any in-depth review, but several major points of principle and of scope were raised that warranted the panel's review. Without more detailed outlines it is not possible to recommend or project the precise direction of these efforts for more than the next couple of years. What follows is a review of the recent progress, current plans, and preliminary proposals of the NNDC and LBL in the areas of electronic publication and dissemination.

An excellent example of a fruitful, intermediate-stage accomplishment is the NNDC's development of computer-generated fax data. Figure 4 is an actual computer-generated fax of a page for publication of the Nuclear Data Sheets. Since the production process for this report itself involves additional stages of optical reproduction, one can appreciate the high-quality graphics presentation that is available via the original computer-to-fax transmission. This mode circumvents one of the primary restrictions of on-line access arising from the limited capabilities for high-resolution output available in terminals and workstations typically used by researchers.

Two additional major points concerning electronic publication and dissemination are warranted. First, the NNDC is incorporating computer-to-fax capability within the on-line access system. Second, since the initial computer file is a PostScript file (which has been converted to G3 FAX bit map format), researchers desiring a laser-printed copy could, in principle, download the Postscript file itself and print it locally. As a corollary, with this second feature, the researcher could, in principle, edit or add to new results and quickly obtain an updated, 
Figure 4 Example of an actual computer-generated fax of a page for publication in Nuclear Data Sheets.

${ }_{48}^{121} \mathrm{Cd}_{73}$

MUCLEAR DATA SHEETS

${ }^{121} \mathrm{Cd}$ from ${ }^{121}$ Ag B-Dechy 82 Fo10.82A129
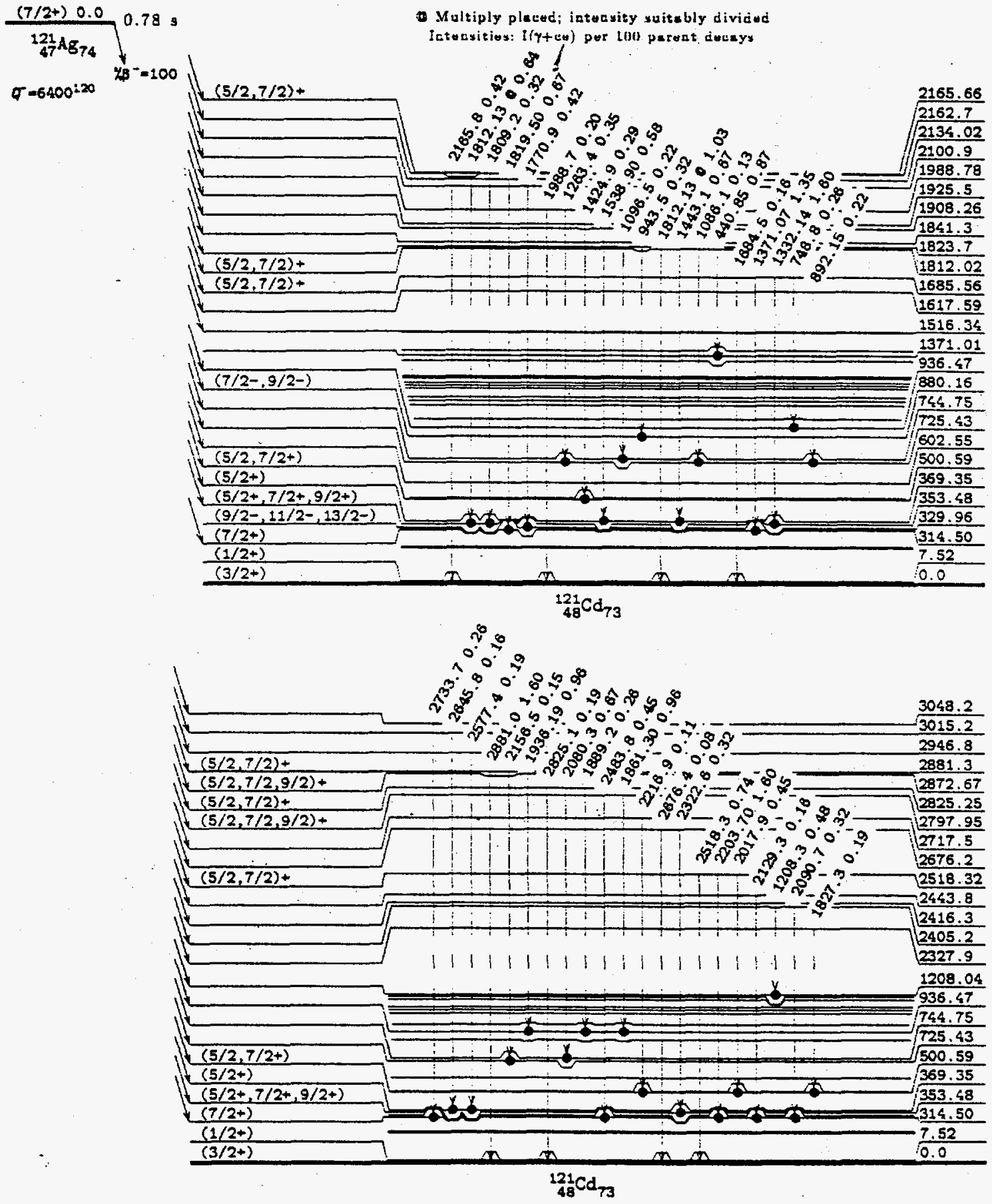
publication-quality figure. The appeal of this corollary is that several of the tedious and error-prone steps of manual transcription can be circumvented.

\section{Proposals from BNL and LBL}

The panel heard a report from the NNDC on the progress on, and plans for developing, the AEGIS system for electronic access to and editing of ENSDF. This system offers a menu-driven, window-oriented data management environment for evaluators. A test version of AEGIS has been installed at three laboratories, where evaluators are currently testing it. Based on their feedback, additional developments are contemplated. The AEGIS system is proposed as a core system for the eventual electronic publishing prototype to be developed by the NNDC. The next proposed steps include the following:

1. Complete AEGIS so that it is a fully functioning evaluation tool.

2. Develop a sophisticated and user-friendly display package for use with AEGIS in the evaluation and review process.

3. Modernize the computer-based manuscript production package.

4. Develop a database system for the storage and retrieval of evaluation manuscripts for access via the NNDC on-line data service.

5. Optimize networking and transmission modes.

Initially, Steps 1 and 2 will serve primarily evaluators and reviewers as AEGIS evolves toward a more user-friendly system. At some stage, a fully tested AEGIS could begin serving the needs of the user community. Step 3 would enhance efficiency in the production of manuscripts and eventually streamline the entry of graphical representations of evaluated data into the database described in Step 4.

All steps are essential to making progress toward eventual electronic publication, while enhancing the manuscript production process in the near term. The NNDC proposal would take 5 to 6 years to accomplish with no increase in funding. With an increment of $\$ 340,000$ these steps could be accomplished in 2 years.

The panel heard a preliminary proposal from LBL for an electronic publication and dissemination system that dovetails with their existing efforts to produce a new edition of the Table of Isotopes largely through electronic publication. The LBL proposal incorporates the achievements of Prof. Craig Stone of San Jose State University, who has been pioneering the development of a personal-computer-based Chart of the Nuclides. While this preliminary proposal outlines a future system based on ENSDF and emphasizing convenience of use, it does not accommodate the intermediate-term needs of continuing publication of the Nuclear Data Sheets in hard copy. Nevertheless, LBL's progress toward the electronic publication of the Table of Isotopes represents the development of important software that accesses the ENSDF and presents the data in compact graphical form. Figure 5 presents a sample of a nuclear level scheme produced directly from ENSDF in a format suitable for publication in the Table of Isotopes. The software that produced this figure has been developed in Fortran, which means that some software development will be required to produce a personal-computer or workstation version. 
Figure 5 Example of a nuclear level scheme produced directly from ENSDF in a format suitable for publication in the Table of Isotopes.

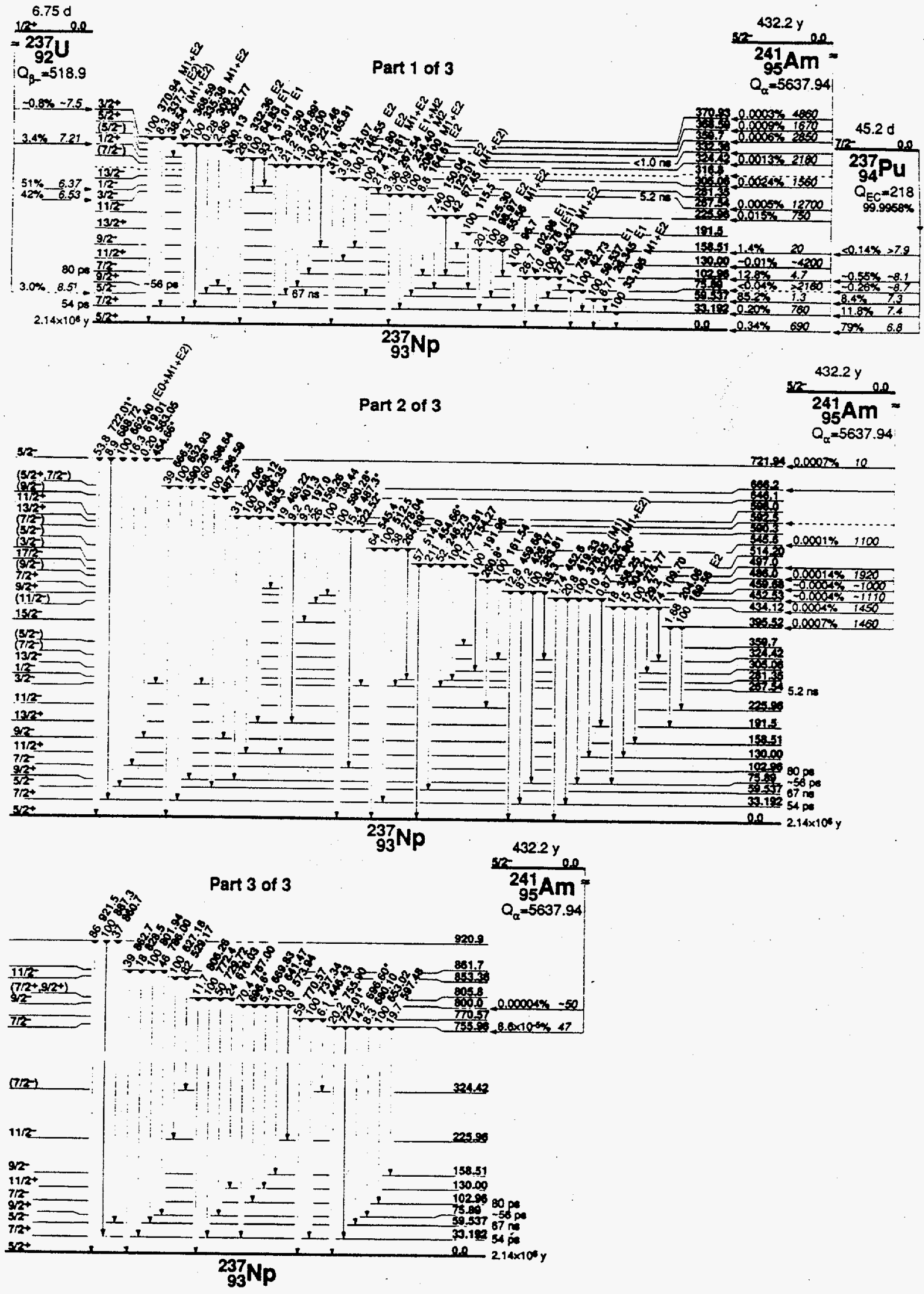


The principal steps envisioned to achieve a user-friendly system accessing the entire ENSDF with convenient high-quality graphics output are as follows:

1. Develop a graphical interface;

2. Enter ENSDF into the database management system; and

3. Develop software for presentation of tabular and graphical material either on screen or via printer.

The plan includes the development of tools for evaluators to enter data into ENSDF, which represents duplication of NNDC's AEGIS system. Overall these steps would take about 4 years to accomplish with the existing scientific personnel, but this time could be shortened to about 2 years with the addition of 1 FTE ( $\$ 300,000$ over 2 years).

While the LBL proposal clearly represents the more visionary concept of a utilitarian electronic system for the researcher in the future, it is also necessary to continue to streamline the publication of the Nuclear Data Sheets in the intermediate term. The panel was not sufficiently informed to make a recommendation supporting implementation of either of these proposals. While the AEGIS proposal does address the intermediate time frame in which publication of the Nuclear Data Sheets continues to be a major means of distributing the information in ENSDF, the preliminary responses of the evaluators who have started to use AEGIS did not support a positive recommendation for implementation from the parnel. Given the current and anticipated funding scenarios, in which it is possible that no new funds will become available in the near term for nuclear data activities, the fact that the NNDC estimates it would take 5 to 6 years to implement AEGIS also diminishes the viability of this proposal. However, the concept presented by LBL was just that, and the panel does not feel qualified to endorse the LBL proposal without additional detailed information. Therefore, the panel recommends that the U.S. Network work together to present a cohesive, detailed proposal for future electronic publication and dissemination of the evaluated nuclear structure data that can address the following:

1. The needs of evaluators, including, for example,

a. No need for pre-review processing of the evaluation at NNDC;

b. Availability of additional checking procedures and other aids to the evaluator;

c. Sophisticated and user-friendly display package;

2. The needs of users, for example,

a. Basic nuclear scientists, both experimentalists and theorists, who are interested in the most current data;

b. Applied scientists, for whom the reliability and completeness of the data are most important;

c. User-friendly electronic access to data and high-quality graphics capabilities;

3. The need in the intermediate term for production of Nuclear Data Sheets in hard copy;

4. Compatibility with current and any future on-line access networks.

The panel does recognize that implementing such a program will be difficult, especially given current expectations for resources. However, the panel believes there is considerable talent in the U.S. Network and clear enthusiasm for such a project, and hopes that such a project can come to fruition by reallocation of resources throughout the entire U.S. Network.

One major issue yet to be resolved is whether a centralized or a distributed processor environment is to be preferred. The NNDC proposal favored the former, while that of LBL favored the latter. With the advancing technology and reduced costs projected for scientific workstations, it is highly likely, in the panel's view, that a centralized facility working to maintain software and to manage continuously updated databases, coupled with advanced scientific workstations for local processing of data and creation of graphic and tabular output for on-screen or printed presentations, will become an increasingly attractive scenario in the next few years. 
Consequently, some merging of the best features of these two preliminary proposals appears to be the optimum pathway to achieving these goals in the next 5 to 10 years. The panel therefore strongly encourages the program manager to bring into closer coordination the database management, on-line access, and software development services of the various U.S. centers so that an optimized, user-friendly, information and research-oriented database environment can be developed within the next few years.

\section{MacNuclide}

The panel heard a presentation from Prof. Craig Stone, San Jose State University, on the development of his personal-computer-based "MacNuclide" nuclear data environment. Discussed in the 1990 panel report, it is an interactive and user-friendly electronic version of the Table of Isotopes with a plethora of potential uses. It offers exciting possibilities as a teaching as well as a research tool. Many of the features being developed for MacNuclide were discussed as features that will be available in the on-line system proposed by LBL and discussed above.

The development of MacNuclide is now supported by a DOE grant, and Prof. Stone works in close collaboration with the LBL group. Recent progress includes development of the flexibility for the user to incorporate additional data files, such as new research results, into the MacNuclide database environment. The software development for the MacNuclide system is on schedule, and a test version is expected during the mid-1992. The panel looks forward to release of this version.

\section{THE USER'S NEEDS}

Easily accessible, accurate, current nuclear data are becoming increasingly important in today's highly technical, multidisciplinary world. The uses of such information cut across disciplines as diverse as basic research in cosmology, astrophysics, and nuclear science and have applications in reactor design, radiotherapy, and geology. Often the evaluator does not even know the end use of this effort. At the same time, many users, being unqualified to judge independently the reliability of the data, are completely dependent on the evaluation. In contrast, users in the field of nuclear science itself may be most interested in the latest information of a specific type. Thus a versatile, accurate, current, and user-friendly system is necessary. Therefore, the panel reiterates its previously stated recommendations that the nuclear data centers should attempt to ascertain the needs of the user community and make their evaluated data as accessible as possible to the broadest constituency of users.

\section{Applications to Applied Fields}

Although this panel is not qualified to assess the needs of the entire user community, it seems appropriate to make a few general statements. Many users are not experts in the various facets of nuclear science. An easily accessible, user-friendly source of accurate information can fulfill their needs. Often this information can be provided in the various tabular publications of the nuclear data centers, such as the Table of Radioactive Isotopes, the Table of Isotopes, and so on. Sometimes more detailed information is desired; therefore, every effort must be made to ensure that the more comprehensive publications (e.g. the Nuclear Data Sheets) and the data files (e.g., ENDF/B, ENSDF, XRAY, MIRD) are constructed so that the desired information can be retrieved in formats useful for a variety of tasks. Often users may wish to make their own calculations based on the retrieved data. Therefore, a retrieval method providing tabular data in "computational format" for additional computer calculations is desirable. 


\section{New Nuclear Data Initiatives in Nuclear Science}

It is essential that the nuclear data centers maintain a close relationship with active experimental and theoretical researchers in the field of nuclear science and that they continually consider how best to accommodate new scientific initiatives in their evaluations. Nuclear science is not a static field and the evaluation of nuclear data should not be static either.

An area of nuclear science currently experiencing rapid growth in the production of data is high-spin nuclear structure. The use of large arrays of Compton-suppressed germanium detectors, which are very efficient at establishing long cascades of coincident gamma rays, has led to an explosion of high-spin data for rotational nuclei. As many as 200 levels are known for some nuclei arranged in up to 20 rotational cascades. The advent of the next generation of Compton-suppressed germanium arrays, such as GAMMASPHERE and EUROGAM, which will soon begin their initial phase of operations, promises a continued growth of high-spin nuclear data.

While high-spin data probably are not of current interest to the applied users of nuclear data, they are of considerable interest to experimental and theoretical nuclear structure scientists. Since this field grows so rapidly, access to current data is essential. Recently, several high-spin databases have been established by practitioners in this field, to compile subsets of current high-spin data in a convenient format for a variety of analyses. Such databases have bypassed the Nuclear Data Network mainly because the users always need the latest data in a format convenient for calculating other nuclear structure quantities.

The panel recommends that the Nuclear Data Network investigate the following with the high-spin nuclear structure community:

1. The possibility of providing the current data of the various high-spin databases to the nuclear science community through the Nuclear Data Network;

2. A method of maintaining an up-to-date high-spin database; and

3. A technique for providing such data to interested users in a tabular format that can be used directly for computing secondary quantities of scientific interest.

The NNDC has successfully developed the tools to make nuclear structure databases accessible on line. The panel believes that it is appropriate to use this expertise to enhance the access to the high-spin data, for example, with assistance from the researchers.

Another nuclear science initiative that will provide rapid growth of nuclear data is the introduction of radioactive nuclear beams. The use of accelerated secondary beams, discussed both in the United States and abroad, will provide an extension of nuclear data farther from stable nuclei. For example, the number of nuclei available for study may be increased by as much as 50 percent. Already the nuclear data centers can provide information necessary to establish the most interesting physics in these new nuclei, thus helping to justify the construction of such facilities. Nuclear astrophysicists will also need access to data that are far from stable nuclei, since the paths of rapid proton- and neutron-capture nucleosynthesis (the rp- and r-processes) lie beyond the limits of nuclei accessible to study with stable beams and stable targets. The panel recommends that the Nuclear Data Network examine how it incorporates results of nuclei far from stability and that it determine whether current methods will be adequate with the advent of major new facilities with radioactive beams.

The panel believes that interacting with scientists in areas of high current research will not necessarily impose extra responsibilities on the Network. Rather, working with the communities that produce new data should help make the future evaluation process, which will include these new data, more efficient. 


\section{5 \\ The Future of the Panel}

This is the final report of the Panel on Basic Nuclear Data Compilations under the auspices of the National Research Council. However, the present panel is convinced that it is important to continue to have an advisory body that (1) regularly examines the current status of nuclear data evaluations, their dissemination to the user communities, the uses of the evaluations, the needs of those users to ensure they are being met, and future needs for evaluation and dissemination of nuclear structure data, and (2) makes recommendations concerning these issues.

The Panel on Basic Nuclear Data Compilations has existed for about 20 years, originally under the leadership of Prof. Harry Gove. The original focus of this panel was the timely evaluation and publication of A-chains. While progress still needs to be made to attain the goal of a 5-year cycle time, efforts have been made over the years to reduce the cycle time and to make the database as a whole as current as possible. The adoption of continuous evaluations, in particular, should have considerable impact on the average age of the A-chain evaluations, once this mode of evaluation is fully implemented. In 1985 there were 117 mass chains for which the literature cut-off date was more than 5 years old; now there are 84 for which the literature cut-off date is earlier than 1986. The average age of the ENSDF database is less than it was in 1985. Unfortunately, the number of highly dated A-chain evaluations has not changed over this period, with essentially the same number with a literature cut-off date more than $\mathbf{1 0}$ years old. Also, the time in the pipeline has, if anything, increased over the past years. Obviously, considerable work needs to be done to achieve the goal of a 5-year cycle time.

Probably the major advance in the issues of concern to this panel has been the ability to access the nuclear reference and databases via a variety of computer networks. The NNDC has been successful in implementing on-line access, advertising its availability, and making it user-friendly. This is the first step in revolutionizing the dissemination of nuclear structure data, a process that the panel hopes will continue to improve. In particular, the panel has recommended that the U.S. Network prepare a detailed proposal of plans for a state-of-the-art, user-friendly, electronic system for evaluation, production, and dissemination of nuclear structure data. The panel hopes discussions will continue between the Nuclear Data Network, the program manager, and a future advisory body on how to achieve increased efficiency in nuclear data evaluation and publication, how to expand on-line access to the nuclear databases, and how to accomplish the transition to electronic publication and dissemination of the evaluated data.

The present panel met briefly during the April 1992 meeting of The American Physical Society. The panel discussed measures to reduce the time in the production pipeline, in particular, attempts to reduce the review time. The panel reviewed the number of full, updated, and continuous evaluations completed by each center, the number of reviews completed by each center, and the efforts of the Network to minimize the number of A-chains that are unacceptably out of date. The panel also discussed the progress on the Table of Isotopes.

The panel would like to thank all of the members of the U.S. Nuclear Data Network and Prof. Craig Stone for sharing with the panel their accomplishments, frustrations, and inspirations with regard to nuclear data evaluations. The panel is also grateful to the National Research Council, and in particular to Drs. G. Cynthia Carter and Robert L. Riemer for their efforts on behalf of this panel. 


\section{AGENDA \\ JOINT MEETING OF THE USNDN AND THE \\ PANEL ON BASIC NUCLEAR DATA COMPILATIONS \\ OCTOBER 3--4,1991 \\ OAK RIDGE NATIONAL LABORATORY \\ Conference Room, Building 6000}

October 3, Thursday

9:00 a.m.--10:00 a.m.

USNDN Center Reports ( 10 min. each)
a. TUNL
D. R. Tilley
b. INEL
C. W. Reich
c. LBL
E. Browne
d. ORNL
M. J. Martin
e. BNL
M. R. Bhat

10:00 a.m.--10:15 a.m.

Report on the International Nuclear

Structure \& Decay Data Network M. R. Bhat

a. Coding of $A<45$ into ENSDF

b. Continuous evaluations

c. Re-assignment of A-chains

d. Next NSDD meeting

$10: 15$ a.m. $--10: 30$ a.m.

Nuclear Data for Applications S. Pearlstein

B $\quad$ R $\quad$ E $A$ A

$10: 45$ a.m. $--11: 00$ a.m.

Nuclear Data for Astrophysics

11:00 a.m.--11:30 a.m.

High-spin Data Base J. D. Garrett

$11: 30$ a.m. $--12: 00$ noon

Table of Isotopes--Progress R. B. Firestone

Report

$12: 00$ noon- $-12: 15$ p.m.

Electronic Wall Chart C. A. Stone -

L $\quad$ U $\quad$ N $\quad$ C $\quad$ H 
$2: 00$ p.m. $--2: 15$ p.m.

Report on the NSAC Subcommittee J. A. Cizewski on Nuclear Data Needs of the S. Pearlstein 1990 's

$2: 15$ p.m. $--3: 15$ p.m.

Publication of the Nuclear Data Sheets(NDS)

a. Review of A-chains M. J. Martin

b. Time needed to process A-chains

J. K. Tuli

c. Size of the A-chains in the NDS

J. K. Tuli

AEGIS System--Progress

S. Pearlstein

Report

On-line Access---

Pre-publication evaluations \&

S. Pearlstein other partial evaluations

B $\quad$ R $\quad$ E $\quad$ A $\quad$ K

3:30 p.m.--5:00 p.m.

Electronic Publishing

S. Pearlstein

R. B. Firestone

C. A. Stone

5:00 p.m.--6:00 p.m.

other Business

$6: 00 \mathrm{p} \cdot \mathrm{m}$.

Adjournment

October 4, Friday

9:00 a.m.-5:00 p.m. Panel Executive Session 


\section{COMMISSION ON PHYSICAL SCIENCES, MATHEMATICS, AND APPLICATIONS}

2101 Constitution Avenue Washington, D.C. 20418

SCIENTIFIC AND TECHNICAL INFORMATION BOARD

(202) $334-2755$

September 1990

PANEL ON BASIC NUCLEAR DATA COMPILATIONS

MEMBERSHIP

Jolie Cizewski, Chair (1992)

Associate Professor

Department of Physics and Astronomy

Rutgers-The State University

P.O. Box 849

Piscataway, New Jersey 08854

(201) $932-3884$

Richard F. Casten (1992)

Physics Department

Brookhaven National Laboratory

Upton, New York 11973

(516) 282-3979

Robert E. Chrien (1991)

Department of Physics

Brookhaven National Laboratory

Upton, New York 11973

(516) 282-3903

Secy: $\quad x 3980$

Robert C. Haight (1992)

MS-D406, Group P-15

Los Alamos National Laboratory

Los Alamos, New Mexico 87545

(505) 667-2829

John A. Harvey (1991)

Building 6010, MS-6356

Post Office Box 2008

Oak Ridge National Laboratory

Oak Ridge, Tennessee 37831-6356

(615) 574-4489
Kirby W. Kemper (1993)

Department of Physics

Florida State University

Tallahassee, Florida 32306-3016

(904) 644-2585

\section{Special Guest (now member)}

James P. Vary

Department of Physics

Iowa State University

Ames, Iowa 50011

$\underline{\text { Staff }}$

G. C. Carter

Staff Director

Scientific and Technical Information Board

National Research Council

2101 Constitution Avenue N.W.

Room $H A 458$

Washington, D.C. 20418

(202) $334-2755$

$F A X \quad$ (202) 334-2791

Bitnet: CCARTER@NAS

(appointment to Panel pending approval) 


\author{
AGENDA \\ JOINT MEETING OF THE USNDN AND THE \\ PANEL ON BASIC NUCLEAR DATA COMPILATIONS \\ OCTOBER $4--5,1990$ \\ IDAHO NATIONAL ENGINEERING LABORATORY \\ Conference Room 120, INEL Research Center, \\ Idaho Falls
}

OCTOBER 4, THURSDAY

$9: 00$ a.m. $--10: 30$ a.m.

USNDN Center Reports
a. Univ. of Pennsylvania
F. Ajzenberg-Selove
b. TUNL
D. R. Tilley/H. Weller
c. INEL
C. W. Reich
d. LBL
R. B. Firestone
e. ORNL
M. J. Martin
f. BNL
M. R. Bhat

Report on the International Nuclear Structure \& Decay Data Network M. R. Bhat

10:30--12:00 noon Publication of the Nuclear Data Sheets(NDS)
a. Review of A-chains
M. J. Martin
b. Time needed to process A-chains
J. K. Tuli
c. Size of the A-chains in the NDS
J. K. Tuli

ENSDF Publications
a. Table of Isotopes
R. B. Firestone
b. Nuclear Wallet Cards
J. K. Tuli

$12: 00$ noon

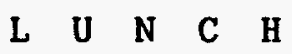

2:00 p.m.--3:00 p.m.Evaluation Tools: the AEGIS System
C. L. Dunford
C. L. Dunford
C. A. Stone

On-line Access

Electronic Wall Chart 
3:00 p.m.--6:00 p.m.Mass-chain Evaluation Productivity

a. USNDN Response on Increase in Productivity

S. Pearlstein

b. Proposal for a Short Evaluation Cycle

c. Comments by USNDN Members

R. B. Firestone

M. J. Martin

C. W. Reich

D. R. Tilley

Other Business

6:00 p.m. Adjournment

OCTOBER 5, Friday

9:00 a.m.-5:00 p.m. Panel Executive Session 


\section{AGENDA}

v.S. NUCLEAR DATA NETWORK MEETING

IDAHO NATIONAL ENGINEERING LABORATORY

Conference Room 7, Willowcreek Building,

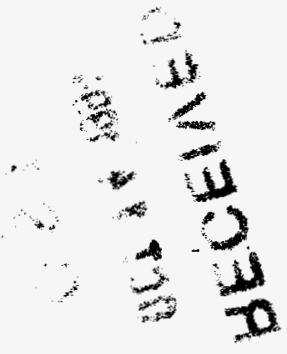

Idaho Falls

OCTOBER 2, TUESDAY

9:00 a.m.-6:00 p.m. Formats \& Procedures Subcommittee Meeting

.OBER 3, WEDNESDAY

9:00 a.m. $-6: 00 \mathrm{p} \cdot \mathrm{m}$. Approve Agenda and Minutes S. Pearlstein

Discussion on:

a. Philosophy of A-chain Evaluations, their Content and Evaluation Productivity

b. Recommendations of the $F \& P$ Subcommit tee

c. Size of the A-chains in the Nuclear Data Sheets.

J. K. Tuli

d. Review of A-chains

M. J. Martin

e. Other Business

6:00 p.m.

Adjournment 